\title{
Fifteen ways of looking at a pointing gesture
}

\author{
Kensy Cooperrider
}

\begin{abstract}
:
The human pointing gesture may be viewed from many angles. On a neutral description, it is an intentional movement, often of the hand, by which one person tries to direct another's attention toward something - it is a bodily command to look. But this definition is only a start. Pointing may also be seen as a semiotic primitive, a philosophical puzzle, a communicative workhorse, a protean universal, a social tool, a widespread taboo, a partner of language, a part of language, a fixture of art, a graphical icon, a cognitive prop, a developmental milestone, a diagnostic window, a cross-species litmus test, and an evolutionary stepping-stone. These fifteen ways of looking highlight the diverse dimensions of one our most unassuming, ubiquitous behaviors. Pointing appears so widely, and in so many guises, because of what it embodies: a distinctively human preoccupation with attention.
\end{abstract}

Keywords: pointing; gesture; reference; communication; culture; child development; animal communication

\section{Word counts:}

abstract: 140

main text (including legends, tables, and footnotes): 13,889

references: 6600

\section{Contact:}

Kensy Cooperrider

kensycoop@gmail.com

Last updated: Sept 10, 2021 


\section{Introduction}

Leonardo da Vinci had a number of fascinations: water, trees, shadows, optics, anatomy, geometry, and, according to a recent biographer, the human pointing gesture (Isaacson, 2017). In several of his paintings and sketches, figures aim their index fingers upward or outward, often toward something out of frame. In The Last Supper (1495-96), the apostle Thomas points heavenward; in the Paris version of the Virgin of the Rocks (1483-86), a winged angel points to the left; in A Woman in a Landscape (1518-19), sometimes known as the "pointing lady" sketch, a solitary subject points rightward; in Saint John the Baptist (1513-16), the figure directs a beguiling smile at the viewer and a swooping finger at the sky (Fig. 1). The upward pointing gesture, considered an allusion to the divine, was a signature of Leonardo's. When the painter Raphael paid homage to Leonardo in his School of Athens (1509-11) fresco, he portrayed Plato in Leonardo's likeness and depicted him pointing up (Isaacson, 2017, p. 449).

Why would a mind that compassed and canvassed so much take interest in such an apparently unremarkable gesture? We can only guess. Perhaps his fascination with pointing grew out of his fascination with the postures of the hand. He certainly understood the gesture's role in social interaction, its central place among the forms of bodily communication he studied throughout his life. Likely he recognized pointing's capacity to wrench attention - a capacity that, as a painter, he could appreciate. Speculatively, he also seems to have registered something enigmatic about the gesture. As one scholar noted: "Mystery to Leonardo was a shadow, a smile, and a finger pointing into darkness" (Clark, 1993, p. 250). 


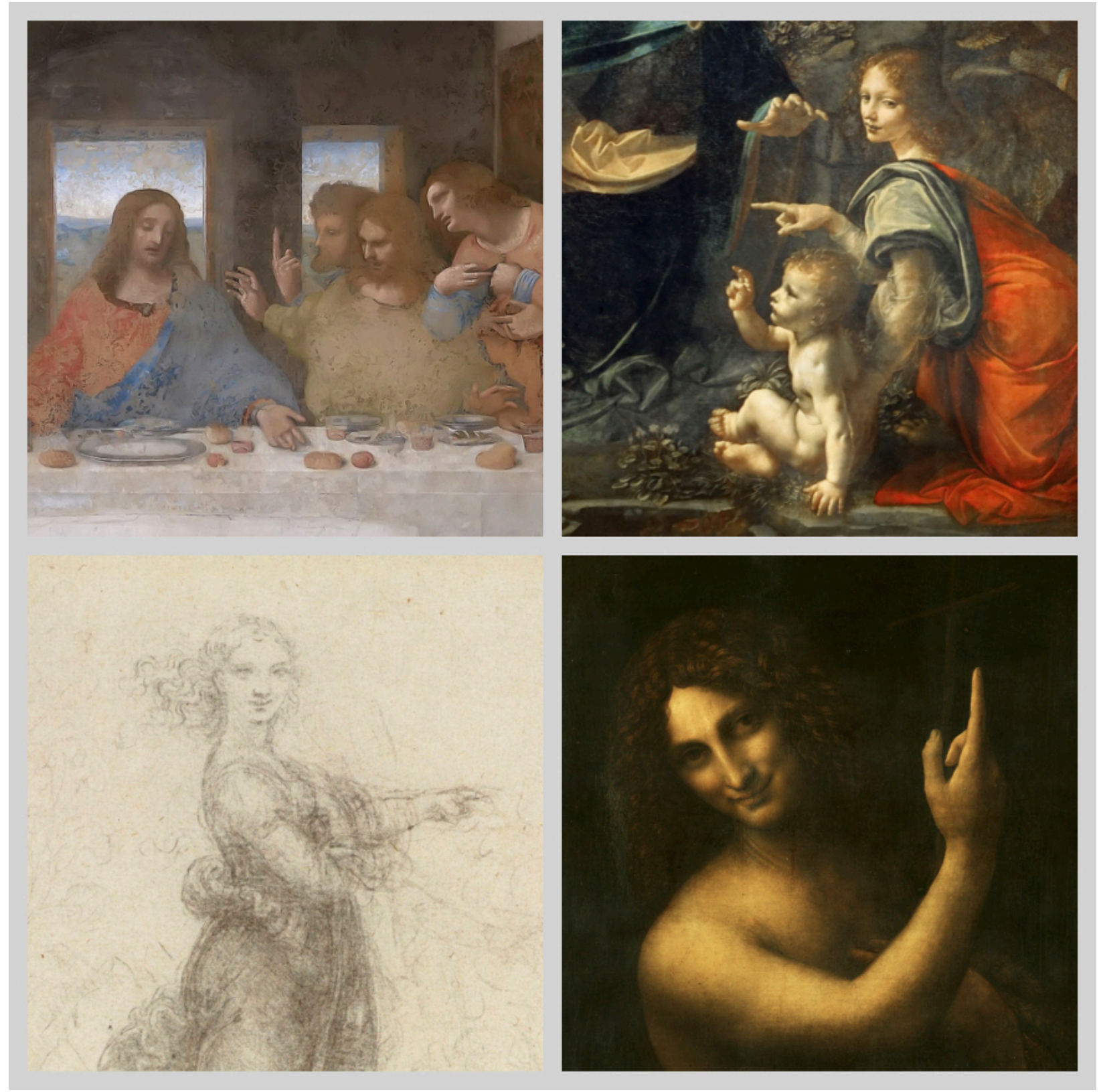

Fig. 1. A selection of pointing gestures in the art of Leonardo da Vinci. Top left: Detail of The Last Supper (1495-96) mural in which the apostle Thomas points upward (Image: public domain). Top right: Detail of the Virgin of the Rocks (1483-86) painting (Paris version), depicting an angel pointing to baby Jesus (Image: public domain). Bottom left: Detail of a sketch known as a Woman in a Landscape (1518-19) (Image: Royal Collection Trust / (C) Her Majesty Queen Elizabeth II 2019). Bottom right: Detail of the painting Saint John the Baptist (1513-16) (Image: public domain). 
Whatever the reason, Leonardo is not the only one to see something special in pointing. Philosophers, anthropologists, linguists, psychologists, semioticians, educators, primatologists, neurologists, and others have all keyed on the gesture at one time or another. Pointing enters into discussions about cross-cultural etiquette, sign languages, neurological disorders, the nature of meaning, and what separates man from brute; it features in diagnostic manuals, philosophical treatises, travelers' accounts, and animal training handbooks. These diverse treatments show that, for such a seemingly simple behavior, pointing proves to be remarkably multilayered. Here I examine the major ways that pointing has been — and can be-viewed; I separate out these layers and identify the themes that crosscut them.

But what is this humble gesture? How might we define it? On a formal definition, pointing is a bodily movement by which one person tries to direct another's attention toward some target (Cooperrider et al., 2018; see also Clark, 2003; Eco, 1976; Kendon, 2004); it does this by a "movement toward" (Eco, 1976, p. 119) that target. Less formally, pointing is a bodily command to look. In many cultures, the gesture prototypically takes the form of an extended arm and index finger, and much of the research to date centers on index-finger pointing. As we will see, pointing comprises a much broader class of bodily actions, involving not just the hands but also the head, face, and even tools; but, as we will also see, there are certain ways in which index-finger pointing does stand apart.

Three aspects of the present definition bear comment, as they help distinguish pointing from neighboring phenomena (Table 1). A first is that pointing movements are overtly designed to direct attention - they are what is often called "ostensive" (e.g., Moore, 2016; Scott-Phillips, 2014; Wharton, 2009). When people are communicating, they shift their gaze, turn their heads, twist their torsos, and reach toward things around them. Attending actions like these make clear 
what the mover is attending to; they "give off" information about the mover's attentional state (Goffman, 1959), and may re-orient others' attention as well. But pointing is different: it is a means by which people openly "give" information about their attentional state and thus try to manipulate the attentional states of others. A second key aspect of the present definition is that pointing involves a "movement toward," which projects a vector or other "imaginary form" toward a target (Hassemer \& McCleary, 2018; Talmy, 2017). There are other ways of directing attention to things: one can brandish something, tap a spot on a wall, or place an object in someone's attentional field (Clark, 2003). Such indicating gestures are all attention-directing but they are not pointing as typically understood. A third important aspect—albeit an implicit oneis that the primary function of pointing is to direct attention; it may have other secondary functions, as discussed below, but attention-direction is paramount (Kendon, 2004). Pointing thus contrasts with other spatially anchored gestures — beckoning and begging, for instancethat involve directing attention to a target but which primarily serve other functions. Finally, it bears emphasis that, though pointing commonly_and prototypically_involves an extended index finger, this is an incidental feature. Gestures that involve index finger extension but do not point in the way just laid are what we might call pseudo-pointing.

With a working definition in hand, we can now consider the different ways the pointing gesture has been — and may be-understood. I consider fifteen in all, beginning with how pointing is understood in semiotics and philosophy; then turning to how it is seen in multimodal interaction research and anthropology; next to how it is understood in linguistics; then to how it figures in visual culture; and, finally, to how it is seen across various subfields of cognitive science. This treatment aims to connect previously disconnected observations; to identify recurring themes in the treatment of pointing across quarters; to highlight overlooked 
observations; and to draw out new insights, thorny issues, and open questions. In the process, I attempt the fullest portrait yet of a humble gesture that some have nonetheless found mesmerizing.

Table 1. Pointing and its neighbors

\begin{tabular}{|l|l|l|}
\hline Class of behaviors & Description & Examples \\
\hline Attending action & $\begin{array}{l}\text { A bodily action that reveals where } \\
\text { someone is attending. Unlike } \\
\text { pointing, not overtly intended to } \\
\text { direct attention. }\end{array}$ & $\begin{array}{l}\text { gazing; turning head; turning } \\
\text { torso; reaching }\end{array}$ \\
\hline Indicating gesture & $\begin{array}{l}\text { A bodily action in which someone } \\
\text { overtly tries to direct attention to a } \\
\text { target. Unlike pointing, does not } \\
\text { involve a "moment toward." }\end{array}$ & $\begin{array}{l}\text { showing; offering; tapping; } \\
\text { placing }\end{array}$ \\
\hline Pointing gesture & $\begin{array}{l}\text { A bodily action in which someone } \\
\text { overtly tries to direct attention to a } \\
\text { target by "moving towards" it. }\end{array}$ & $\begin{array}{l}\text { index-finger pointing; whole- } \\
\text { hand pointing; head-pointing; } \\
\text { lip-pointing }\end{array}$ \\
\hline $\begin{array}{l}\text { Spatially anchored } \\
\text { gesture }\end{array}$ & $\begin{array}{l}\text { A bodily action that involves } \\
\text { directing attention to a target. Unlike } \\
\text { pointing, does not primarily function } \\
\text { to direct attention. }\end{array}$ & $\begin{array}{l}\text { beckoning; begging; palm- } \\
\text { presentation gestures; "halt" } \\
\text { gestures }\end{array}$ \\
\hline Pseudo-pointing & $\begin{array}{l}\text { A bodily action that uses the index- } \\
\text { finger extended handshape but does } \\
\text { not involve pointing. }\end{array}$ & $\begin{array}{l}\text { "nomination deictic"; "semi- } \\
\text { pointing"; finger-tip probing; } \\
\text { shushing gestures }\end{array}$ \\
\hline
\end{tabular}

\section{A semiotic primitive}

Pointing has often been singled out as one of the most basic ways a person can convey something to another. Wilhelm Wundt considered pointing "not only the simplest, but also the most primary gesture in the effort to communicate" (Wundt, 1973, p. 74). Ludwig Wittgenstein 
wrote: "If I want to show a person the way I point my finger in the direction he is to follow, and not the opposite one... It is in human nature to understand pointing a finger in this way. And thus the human language of gestures is in a psychological sense primary" (Wittgenstein, 2005, p. 46, original emphasis). Collinson (1937) summarizes the idea of pointing as a semiotic primitive plainly: "The simplest and most universal form communication is gesture and the simplest kind of gesture is the act of pointing" (p. 17). Remarks like these belong to a long tradition in which pointing has been considered "ontologically primeval” (Haviland, 1993, p. 12).

Some pronouncements about the primitive nature of pointing have had practical motivations. In 1800 Joseph-Marie Dégerando, a French philosopher and proto-anthropologist, published a guidebook for European travelers who wished to observe "savage peoples" in distant lands (Dégerando, 1800/1969). When encountering natives, he advised, it is best to rely on the "language of action" - that is, gestures. He noted that indicating gestures are the ones whose “effect is most sure, and least subject to ambiguity." He continued: "We must think to describe only when we can not point out" (p. 71; original emphasis). Many participants in "first contact" scenarios seem to have intuited Dégerando’s advice (Hewes, 1974; see also Bonvillian et al., 2009). Martin Frobisher, traveling in the Arctic in the 1500s, described how a native interlocutor conveyed that his party would return in three days by "making signes with three fingers, and pointing to the Sunne" (Hewes, 1974, p. 10). Commodore Byron, describing an encounter with the indigenous inhabitants of Patagonia in 1764, recorded: "During our pantomimical conference, an old man often laid his head down... and afterwards pointed first to his mouth, and then to the hills, meaning, as I imagined it, that if I would stay with them till morning they would furnish me with some provisions" (Hewes, 1974, p. 20). In situations like these, with no shared communicative conventions in place, pointing proves preeminently handy. 
Other pronouncements about the primitive nature of pointing have had theoretical motivations. Pointing has often figured centrally in broad treatments of how humans mean for each other. For Charles S. Peirce, progenitor of semiotics, pointing exemplified one of three fundamental sign types (Peirce, 1940; see Goudge, 1965). In his framework, these types differ in how they evoke their objects: icons bring to mind their objects because they resemble them; symbols bring to mind their objects because of a learned association; and indices like pointing "direct attention to their objects by blind compulsion" (Peirce, 1940, p. 180). An index—whether in the form of a pointing gesture, a thunderclap, a weathervane, or a rap at the door- - "exercises a real physiological force over the attention" (Goudge, 1965, p. 56). Peirce was not interested in human communication in particular, but his trichotomy has since been taken up and refined by those who are. Clark $(2003,2016)$ has distinguished three basic methods of human communication—depicting (using icons), describing (using symbols), and indicating (using indices), while also emphasizing that these methods very often occur in combination (see also Enfield, 2009; Ferrara \& Hodge, 2018). On Clark’s account, one can indicate in a variety of ways — by brandishing or tapping an object (see Table 1) — but pointing is a key exemplar. A related tradition treats pointing as a paradigm case of joint attention, the condition in which two or more people are attending to something together (Kockelman, 2005; Tomasello, 2008). In turn, such accounts view joint attention as an "exemplar of semiosis" and a "condition of possibility for language socialization and cultural socialization more generally" (Kockelman, 2005 , p. 237). Seen this way, as a symbol of our species' capacity for joint attention, the pointing gesture becomes implicated in the very foundations of meaning making. 


\section{A philosophical puzzle}

Simple as it may seem, others have stressed that pointing is less than straightforward. Consider the act of trying to teach someone the meaning of a word by pointing out what it refers to. This is known as ostensive definition, and it has long been a philosophical fixation. In his Confessions, written around $400 \mathrm{CE}$, St. Augustine described it as central to language learning: "When [my elders] named some object, and accordingly moved towards something, I saw this and I grasped what the thing was called by the sound they uttered when they meant to point it out" (Augustine, 1996, I.8). Wittgenstein quoted this passage at the outset of his Philosophical Investigations, and then proceeded to question whether one could really learn language in this way. How, he wondered, could one convey something's properties simply by pointing to it? "Point to a piece of paper.-And now point to its shape — now to its colour... How do you do it?" (Wittgenstein, 1953, section 33). The target of the point is always the same, after all; only its intended meaning changes.

Willard Van Orman Quine shared such worries. He invited readers to imagine themselves in the company of a speaker of an unfamiliar language. As a rabbit hops past, your companion cries "Gavagai!" Can you assume that gavagai means 'rabbit'? And can you confirm that it means 'rabbit' by pointing to other hoppers-by and asking: "Gavagai?" Unfortunately not, wrote Quine, as the meaning of the word, despite the gesture, is hopelessly underdetermined: "Point to a rabbit and you have pointed to a stage of a rabbit, to an integral part of a rabbit, to the rabbit fusion, and to where rabbithood is manifested" (1960, p. 52-53). Anecdotes abound about how pointing gestures in Gavagai-like circumstances have been misconstrued. Reportedly, the indri lemur of Madagascar got its name when a French naturalist, Pierre Sonnerat, recorded a native guide shouting "Indri!" while pointing to one of the animals. But indri in the native language, 
Malagasy, simply means 'Look there!' (see Clark \& Sengul, 1978). The truth of this anecdote remains debated. Hacking (1981) claimed to debunk the story, and questioned whether there has ever been such a "malostension." But the veracity of such stories is beside the point: what is crucial is the observation that a pointing gesture does not single-handedly identify a referent. All it does is say "look in this direction and infer what I'm getting at" (see Tomasello et al., 2007). It is, again, a movement towards a target, but the relevance of that target is left unsaid.

Pointing is puzzling enough when it aims to pick out something right there for all to see-what Quine (1968) referred to as direct ostension. The puzzles multiply when someone points to something right there as a way of referring to something that is not - what Quine dubbed deferred ostension (Borg, 2002; Nunberg, 1993). Quine's examples of the latter involve someone pointing to a car's gas gauge to refer to the gasoline, or pointing to grass to refer to the abstract property of green-ness. Elsewhere, deferred ostension has been called "metonymic pointing" (Cooperrider, 2014; Le Guen, 2011). The idea is that what is actually pointed to - the target, whether person, object, or region of space - serves as a metonymic portal to what is meant - the referent. A commonplace example occurs when a person points to their own chest when referring to 'we' (Cooperrider, 2014) ${ }^{1}$. The fact that people point metonymically makes the meaning of “Gavagai!” all the more inscrutable. It could mean 'brown,' 'furry,' 'animal,' 'lunch,' among countless other associated concepts (Tallis, 2010). The transparency of pointing is - at least sometimes — an illusion.

${ }^{1}$ Even a point to the chest with "I" arguably involves a metonymy, as a conventional location stands for the abstract concept of self. Such an interpretation becomes more compelling when we consider that, in some communities, one can refer to the self by pointing to a different conventional location: the nose (e.g., Davis, 2010). 


\section{A communicative workhorse}

Primitive perhaps, puzzling sometimes — but one thing that is inarguable about pointing is that it is pervasive. The gesture is a workhorse of everyday communication. It has been studied in contexts such as direction-giving (Kita, 2003; Kita \& Essegbey, 2001), doctor-patient interactions (Gerwing \& Li, 2019), work meetings (Mondada, 2007), guided tours (Kendon, 2004), museum visits (Windhager et al., 2011), archaeological digs (Goodwin, 2003), talk show interviews (Cooperrider, 2014), and mathematics lectures (Alibali et al., 2011; Knoblauch, 2008), and it no doubt occurs in countless other contexts. In settings like these, pointing may in fact be the most commonly used gesture type of all, more common than depictive gestures or conventional emblems like the "thumbs up." One group of researchers filmed 25 Aka men in the Central African Republic who were gathered to cook and socialize, and found that pointing accounted for more than $60 \%$ of their gestures (Robira et al., 2018). Similarly, Alibali et al. (2011) examined math lectures in the United States and Japan and found that attention-directing movements_ chiefly pointing, but also other forms of indicating — accounted for more than $60 \%$ of gestures.

Why is pointing so pervasive? The answer likely lies in its several virtues. One is efficiency: Pointing can sometimes offer a degree of spatial precision that is difficult to verbalize (Bangerter, 2004), helping single out a specific mountain on the horizon, or a particular fish in an aquarium. Another virtue is flexibility: Joined with a bit of imagination, pointing is remarkably far-reaching, hardly limited to what is visible and concrete. People readily point through walls (Bühler, 1990); they point as if from somewhere other than where they are standing (Haviland, 1993); they point to temporal landmarks (Cooperrider et al., 2014), and to other entities that exist 
only in the imagination (McNeill et al., 1993; Stukenbrock, 2014); they point to now-empty locations to refer to what was previously there, beginning at a very young age (e.g., Bohn et al., 2015); and they point to metonymic portals, as previously discussed - to the gas gauge to refer to gas but also to a person's house to refer to the person (Levinson, 2007) or to a location on the sun's arc to refer to a time of day (Floyd, 2016). A third virtue is that pointing is quiet, and so can be used in situations where speech would be ill-advised - for instance, to request the salt without interrupting the dinner conversation ${ }^{2}$.

Pointing is widely used, but is it widely understood? In short, yes. Children begin to extract meaning from pointing gestures at a young age (Thompson \& Massaro, 1986), as early as 9 to 12 months old (Behne et al., 2012; Krehm et al., 2014), in fact, and they soon rely on pointing more than words when the two are in conflict (Grassmann \& Tomasello, 2010). So effective is pointing in reorienting children's attention that mothers in the village of Gapun, in Papua New Guinea, try to quiet fussy infants by pointing into the jungle at non-existent pigs (Kulick, 2019). In adults, pointing is processed automatically (Langton \& Bruce, 2000) —as if by “blind compulsion," as Peirce noted — and with a remarkable degree of precision (Bangerter \& Oppenheimer, 2006; Cooney, Brady, \& McKinney, 2018). It speeds communication, helping viewers arrive more quickly at an intended referent (Louwerse \& Bangerter, 2010). Viewers also take pointing gestures into account when interpreting what a vague utterance means: They will read a comment that "the flies are out" as an indirect request if it is accompanied by a point to an open screen door (Kelly et al., 1999). Addressees even process points to empty space: If a speaker regularly points to the left when talking about Shakespeare and the right when talking

2 Pointing is not particularly discreet, however, at least not in its prototypical form. Many have suggested this may be a motivation for non-manual forms of pointing, which are less conspicuous (e.g., Orie, 2009). 
about Goethe, a later change in spatial assignment will confound them (Gunter \& Weinbrenner, 2017; see also Gunter, Weinbrenner, \& Holle, 2015). Similar effects have been found in children as young as 7-8 years old (Smith \& Hudson Kam, 2012). Addressees also appreciate metonymic pointing. Floyd (2016) showed that Nheengatú speakers extracted the time of day from points to the sun's arc; they also tended to repeat the pointing gesture when asked what a speaker "said" and to quietly correct it when it was inaccurate.

Pointing also serves as a communicative workhorse when spoken communication is not possible. It pervades cultural contact scenarios, as mentioned (Hewes, 1974). Goodwin (2003) described the case of Chil, a severely aphasic man who managed complex utterances and narratives with just a few words ("yes," "no," "and") and a lot of points. Pointing is a fixture of the sign systems used in work environments where speech is difficult, such as the sawmill languages of British Columbia (Meissner et al., 1975). It is also a cornerstone of "homesign"the gestural systems of communication that profoundly deaf individuals create when they cannot access spoken language and are not exposed to a conventional sign language like American Sign Language (ASL) (Goldin-Meadow \& Mylander, 1984; see also Kendon, 1980a, 1980b, 1980c). Points remain prominent as sign languages grow in number of signers and become increasingly codified. A corpus analysis of Kata Kolok, a village sign language in Bali, found that $16 \%$ of signs were pointing signs (De Vos, 2014). Comparable percentages have been reported in Auslan (Johnston, 2013a) and ASL (Morford \& MacFarlane, 2003). In fact, the most frequent sign in several sign language corpora is a pointing sign: the first-person pronoun, consisting of an index finger point to the chest (e.g., Fenlon et al., 2014). Pointing is also incorporated into the tactile signing practices used by the deafblind (Edwards, 2015; Kusters, 2017). Invariably, across settings and cultures, in both spoken and signed communication, pointing proves indispensable. 


\section{A protean universal}

Wherever you go, people point; the gesture is, by all accounts, a human universal (Cooperrider et al., 2018; Eibl-Eibesfeldt, 1989). And wherever you go, people point at least sometimes with the extended forefinger ${ }^{3}$. Again, this is the canonical form of pointing in many places, and, accordingly, speakers of many languages refer to the forefinger as the "index finger" or "pointer finger." (The word index — along with indicate, deixis, and deictic - traces to a ProtoIndo-European root meaning 'to show' [“index," n.d.]) Such labels are found not only in English and European languages but also in Iranian (Filippone, 2010), Turkic (Yong-Song, 2016), and Amerindian languages (Trumbull, 1874) — and possibly globally. Why is the index finger used for this purpose, as opposed to some other digit? Some researchers have noted that when the human arm is held vertical and the hand is allowed to dangle, the index finger sticks up relative to the other digits (Povinelli \& Davis, 1994). (In some languages, the forefinger is also known as the "one who stands erect," perhaps alluding to this biomechanical fact [Filippone, 2010].) Whatever the reason, it is clear that when humans need to extend a single finger, it is the forefinger that they prefer. A survey of ten sign languages found that signs that involve extending a single digit overwhelmingly involve extending the index finger; the little finger is a distant second (Woodward, 1982). As mentioned, the association between pointing and the forefinger is so strong that people sometimes label any gesture that involves forefinger extension "pointing." One example is the rhetorical gesture that involves poking the digit upwards while raising an important consideration or new insight. Kendon (2004, p. 142) dubs this the

${ }^{3}$ There is at least one informal report of a group in Papua New Guinea that never points with the index finger (Wilkins 2003, p. 176). Absence is notoriously difficult to demonstrate, howeverand impossible to demonstrate with informal reports. 
"nomination deictic." While the gesture may be "deictic" in the loose sense that it calls attention to something, it does not do this by "moving toward" it; it is thus a form of pseudo-pointing.

Prototypes aside, pointing is remarkably protean. The core function of pointing, again, is to direct a viewer's attention, and this can be done using a number of body parts, in different configurations. The whole hand is an obvious choice. Children use this form of pointing frequently (e.g., Cochet \& Vauclair, 2010), as do adults in certain contexts (Flack et al., 2018). When English speakers point to themselves, they usually use the whole hand, sometimes pressing it against their chest (Cooperrider, 2014). Blind speakers favor pointing with the whole hand, as do sighted people when blindfolded (Iverson \& Goldin-Meadow, 2001). Even when extending digits, other configurations are possible. When pointing to something at one's back, the thumb serves well (Kendon, 2004, p. 218-22). At Disney resorts, employees are trained to point with the index and middle finger joined together, putatively in imitation of Walt Disney's signature cigarette-in-hand pointing technique (Luu, 2017). Genie, a child who was horrifically deprived of any language or communication from a very young age, favored pointing with her middle finger (Looney \& Meier, 2014).

Several have argued that the form of one's pointing gesture is not an arbitrary choice but reflects what one is doing in discourse (Kendon \& Versante, 2003; Kendon, 2004), or how one is construing what one is pointing to (Cooperrider, 2011). On these accounts, the index finger is well suited to singling out a focal object (Kendon, 2004), while, for instance, a full-hand sweep may be better suited for indicating a broader area, such as a mural or group of people (Cooperrider, 2011). (In his Gavagai musings, Quine [1968, p. 189] suggested that one might "indicate the whole rabbit with a sweeping gesture.") Several scholars have proposed rich taxonomies of pointing form; these show how, through a combination of handshape and motion 
pattern, people indicate referents of astounding variety (Hassemer \& McCleary, 2018; Talmy, 2017). In many such cases, the point does not merely direct attention to a target, it also characterizes it (e.g., Kendon \& Versante, 2003), thus combining in one gesture the two basic methods of indicating and depicting (e.g., Ferrara \& Hodge, 2018).

When we look across communities, variations in pointing form multiply. There are no reports of a culture that favors pointing with some finger other than the index - but this digit may not be equally privileged everywhere. In Arrente, an Australian Aboriginal group, some pointing handshapes have dedicated purposes: the "horned hand," for instance, is conventionally used when indicating the general direction in which a place lies, rather than the path used to get there (Wilkins, 2003). Khoisan hunters use different handshapes to point out different things, for instance using a thumb pressed into the index finger to indicate animal tracks (Hindley, 2014). In the Casamance region of West Africa, people sometimes emphasize a point by accompanying it with a finger snap (Krajcik, 2017). In many parts of the world, people point to more distant targets with the arm pitched sharply upward. This convention—reported in Australia (Wilkins, 2003), Madagascar (Sibree, 1884), and Mesoamerica (Mesh, 2021), among many other placeslikely stems from the fact that further locations appear to be higher up in the visual field. The gesture greatly exaggerates this apparent height, however, sometimes aiming almost vertically (Mesh, 2021).

Hands and arms are not the whole story, either. Another natural choice for pointing is the head. Particularly when the hands are occupied, Westerners point by nodding, tossing, or jutting their heads toward targets (Emmorey \& Casey, 2001; McClave, 2000), a behavior that has been proposed as a candidate human universal (McClave et al., 2007). Other cultures accompany their head points with conventional facial actions. The most widespread of these is lip-pointing, which 
involves pursing, protruding, or funneling the lips while looking toward a target of interest; the gesture is globally distributed, with scholarly studies of its use in Panama (Sherzer, 1973), Laos (Enfield, 2001), Peru (Mihas, 2017), Australia (Wilkins, 2003), Nigeria (Orie, 2009), and China (Li \& Cao, 2019), among many other in-passing mentions and informal discussions. Another form of conventional facial gesture is nose-pointing, found in parts of Papua New Guinea (Cooperrider \& Núñez, 2012; Kendon, 1980b). It involves scrunching the face together while aiming the gaze toward a target (Fig. 2). Importantly, all these forms of non-manual pointing involving some marked movement feature - e.g., tossing or nodding in the case of head-pointing, scrunching in the case of nose-pointing. Such "signal establishing" features, as we might call them, turn ordinary attending actions into pointing gestures. 


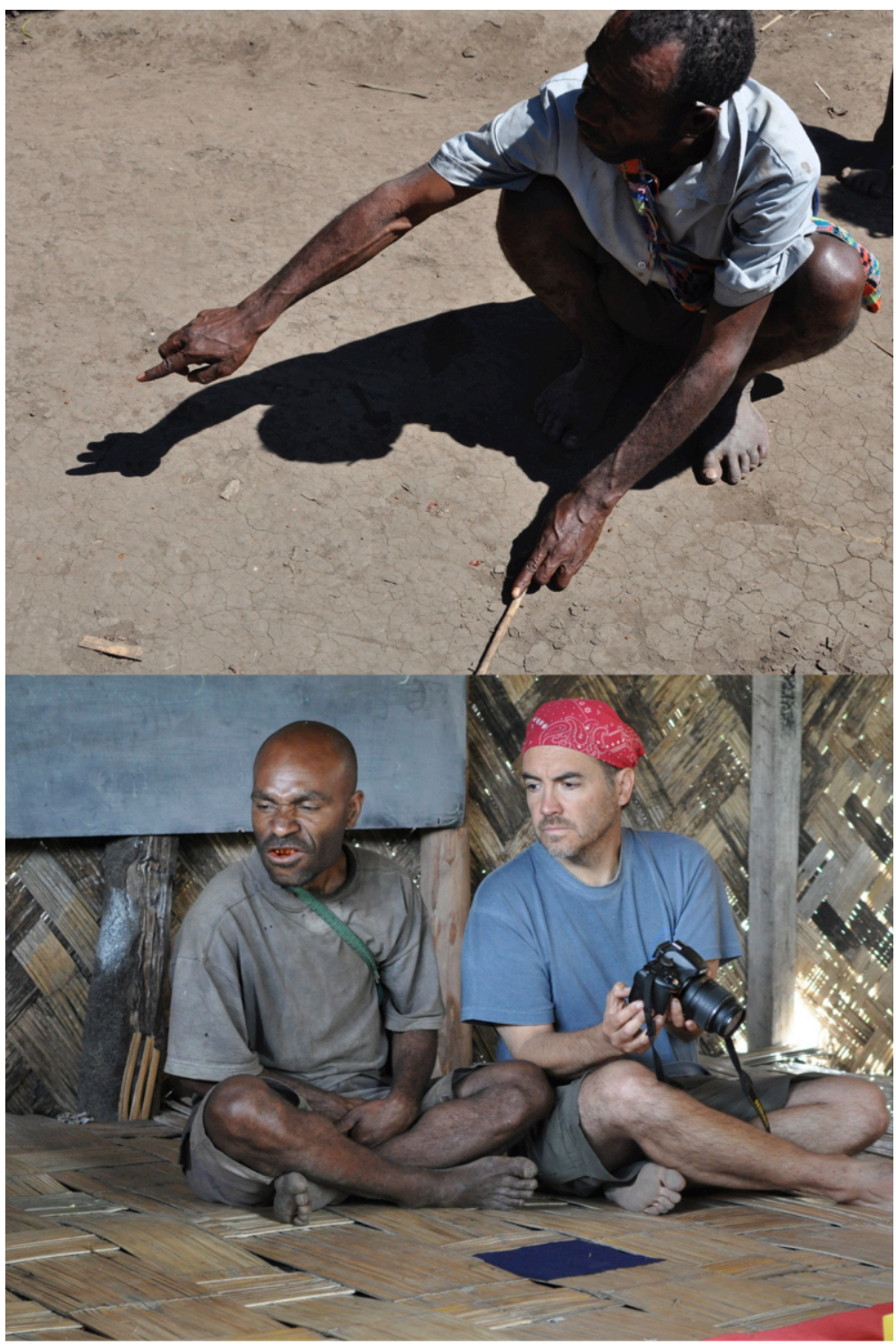

Fig. 2. Two forms of pointing common in the Yupno valley of Papua New Guinea. Top: A Yupno man points with an extended index finger to a depiction on the ground (Image: author). Bottom: A Yupno man (left) nose-points toward an object by directing his gaze and scrunching his face together, a conventional form of pointing in parts of Papua New Guinea (Image: author).

Ethnographers have sometimes reported that non-manual pointing is not only present in a given community, but is preferred over manual pointing (e.g., Bailey, 1942; Everett, 2005; Sherzer, 1983; Sibree, 1884). But only recently have preferences for manual versus non-manual pointing been directly assessed (Cooperrider et al., 2018; Li \& Cao, 2019). Using a referential communication task, Cooperrider et al. (2018) quantified pointing preferences in the Yupno, a 
group in Papua New Guinea that uses nose-pointing; in contrast to Americans, who strongly favored the index finger, the Yupno were equally like to point non-manually and manually. Beyond fingers, hands, and heads, there are still other options for pointing - a laser pointer in modern lecture halls, or a machete in the Brazilian hinterland (Floyd, 2016). Pointing is universal and ubiquitous, but also remarkably protean.

\section{A social tool}

Beyond its primary function of directing attention, pointing often adds shadings of social meaning. Some of these shadings are negative. One of the first close observers of gesture, the classical rhetorician Quintillian, noted that pointing is used not only in indication but also in “denunciation” (Quintillian, 1922, Book XI). Eibl-Eibesfeldt (1989, p. 485) discussed a series of photos depicting a "pointing duel" between two !Kung boys. The threatening tone of pointing has sometimes become the stuff of spectacle, as during the 1959 "Kitchen Debate" when Nixon and Khrushchev exchanged pointing jabs (Larner, 1986). In some places, pointing figures in "aggressive magic": it is believed someone can harm or kill another by pointing a finger or bone at them (Lewis-Williams, 1986; Roheim, 1925). The aggressive flavor of pointing may arise from its resemblance to stabbing (Roheim, 1925, p. 90-92) or, more generally, from the fact that it is conceived as projecting an arrow-like — and thus potentially puncturing — force.

The gesture is also used in the course of reprimand, mockery, and blame. Andrén (2010, p. 222) discusses the example of a young boy scolding a toy, presumably in imitation of having been scolded this way himself (see also Calbris, 1990, p. 118-9). Sherzer (1973) describes how the Kuna of Panama use lip-pointing in the course of mockery. In ASL, the sign for MOCK involves two hands pointing with the index finger, as do other signs that denote negative 
interactions between people (Roush, 2011). In both English and Chinese, idioms use "finger pointing" as an image for accusing and blaming (Yu, 2000).

Pointing can also contribute positive shadings of social meaning. A speaker may point to the previous speaker as a way of showing agreement with what was just said (Healy, 2012; Holler, 2010)—a kind of bodily "Definitely!" Signers use pointing in the same way (Ferrara, 2020). In group conversations, people will point to a present party when referring to something that party said previously, a form of nonverbal "citation" (Bavelas et al., 1992). At least to some observers, pointing conveys authority: Children find people who point more credible than those who do not (Palmquist \& Jaswal, 2012). Pointing is also deployed in greeting, as a jokey way of saying, "Hey there!" or "I see you!" (Sherzer, 1973). In the US at least, such jocular greeting points are sometimes accompanied by a wink, produced with two hands, or are made to look like shooting a gun; they are also common fodder for GIFs (Fig. 3).

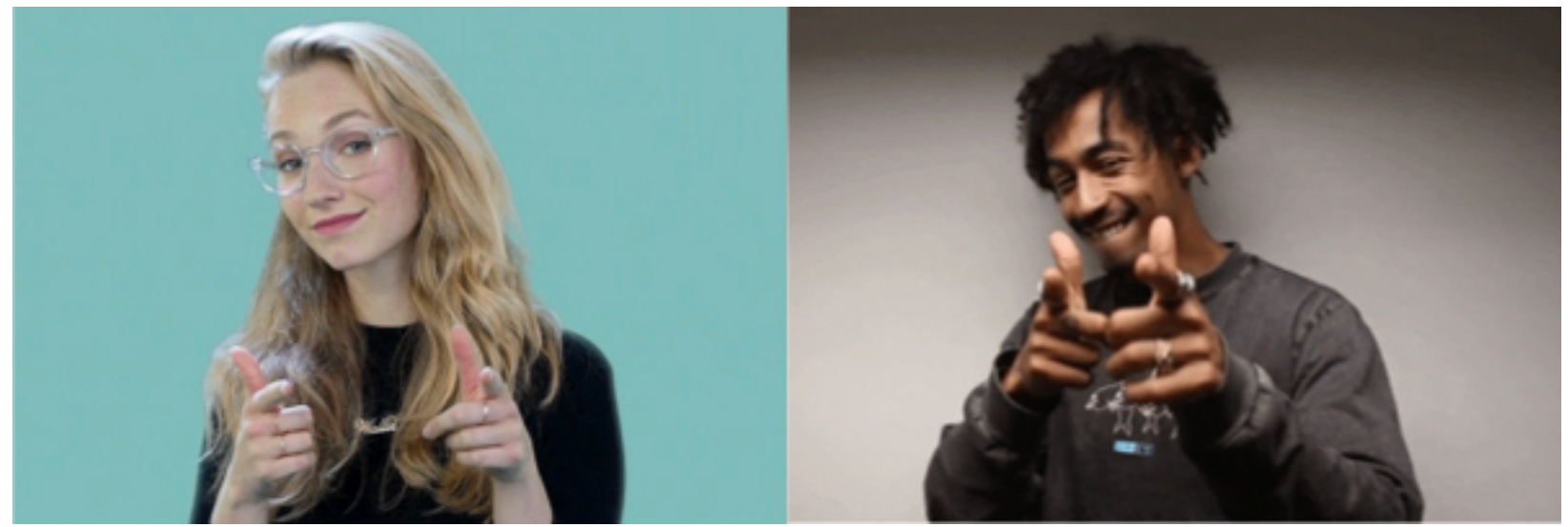

Fig. 3. Stills from GIFs in which pointing functions as part of a jocular greeting or acknowledgment. Such points may be produced with two hands, accompanied by winks, or embellished in other ways. 
Pointing does subtler social work, too. Mondada (2007) describes how, during collaborative work sessions involving shared artifacts, pointing gestures serve as a signal that one wants to hold the floor. The form of pointing itself may also do social work. A robust, forcefully articulated point may convey that the pointer assumes the addressee does not know the location of the target (e.g., a nearby school); in contrast, a meekly articulated point may convey that the pointer is not sure whether the addressee knows the location (Enfield et al., 2007). As with any communicative signal, pointing has a basic meaning that is enriched in context, taking on new shadings depending on who is pointing, when, and how.

\section{A widespread taboo}

As useful and ubiquitous as pointing is, it is also often subject to prohibitions. This may be because of the negative shadings of aggression, reprimand, or mockery that it sometimes carries. Alternatively, it could be because it draws unwanted attention: pointing has been described as a way of "doing focused looking" (Kendon, 2009, p. 359) and a representation of gaze (Cappuccio et al., 2013), and is thus akin to staring. (Part of the logic of pointing - as discussed earlier-is that, unlike mere attending, it announces itself as overt attending.) Travel guides to various parts of the world often assert that pointing to people in particular should be avoided (e.g., Rodgers, 2019). In fact, some have wondered whether a taboo on pointing to people might be universal (Dupoux, 2011) — or might have once been universal, as it is far from clear that such a taboo is still observed. Several studies have examined points to persons in Western communities (e.g., Fenlon et al., 2019; Healy, 2012), suggesting it is not particularly scarce. At the same time, there is evidence that speakers in such groups point differently when indicating people, favoring less "pointy" handshapes such as an open hand (Jarmołowicz- 
Nowikow, 2014; see also Fenlon et al., 2019). The idea that less "pointy" forms are less likely to carry negative meanings may be why politicians sometimes avoid using an extended index finger in their rhetorical gestures_-giving rise, for example, to Bill Clinton's signature gesture, known as the "Clinton thumb" (Shwarz, 2015). It may also be the deeper reason behind the two-fingered “Disney point," stories about Walt's pointing proclivities notwithstanding.

Beyond Anglo-European communities, taboos on pointing are sometimes taken quite seriously. In parts of Africa, pointing with the left hand is considered taboo, as the left side is associated with toileting and other profane functions. Kita and Essegbey (2001) studied this prohibition in Ghana by stopping people in the city of Keta, and asking for directions to nearby locations. The left-hand taboo had clear consequences: People would sometimes strain to point across their bodies with their right hand, or conspicuously tuck their left hand behind their backs, or join both hands together before pointing. Sometimes, while the right hand extended out to point, the left hand, though limp at the person's side, would quietly extend its index finger —a behavior the authors describe as "semi-pointing." (This type of pseudo-pointing, in which the active pointing hand is mirrored by the inactive one, has also been noted in sign languages [e.g., Johnston, 2013a]). In Malaysia, people sometimes use a "forward thumb" handshape to point, to avoid the transgressive edge of the index finger (Mechraoui \& Noor, 2017, p. 69). In some Australian Aboriginal groups, interactions between certain kin relations require circumspection; sometimes in these contexts people will thus point with an elbow, knee, or fist (Green, 2019). What all these varieties share is the apparent drive to defang finger pointing by using a blunter morphology — a phenomenon that Blust (2021) has termed "avoidance deixis."

Many cultures also observe strict taboos about pointing to entities other than people. Among the Zulu, pointing toward objects associated with the ancestors is forbidden; pointing to 
crops will make them die, and the pointer's arm may become diseased (Raum, 1973, p. 437). In Madagascar it is prohibited to point to whales, sharks, or large octopuses with the extended index finger (Astuti, 1995). Among the Kedang of Indonesia, one should not point to Ursa Major, or to still-growing pumpkins (Barnes, 1973, p. 621). A particularly puzzling case is the incredibly widespread taboo on pointing to rainbows (Blust, 2021). This taboo is also observed by the Kedang, who believe that by pointing to a rainbow "one runs the risk of having one's fingers permanently bent" (Barnes, 1973, p. 621). Similarly, in Hungary, it is said the offending finger will wither away (Lee \& Fraser, 2001). Many further variants of this taboo could be adduced; Blust (2021) reports cases of it from 124 cultural communities, spread widely across the globe.

Taboos on pointing with other body parts are also attested. In Laos, there is a general prohibition on pointing with the feet. Wilkins et al. (2007) write that, whereas the taboo on pointing to people is treated somewhat casually, pointing with the feet is "quickly and forcefully sanctioned" (p. 94). In December of 2008, a sculpture of Santa in only his undergarments caused a stir in Palermo, Italy because his crotch was aimed in the direction of a local church (Lorello, 2008). Such examples highlight another reason that pointing my become taboo: it implies some congress between the pointer and the pointed to, and this congress may be seen as untoward. Fanciful and diverse as pointing prohibitions are, all stem from a seemingly universal recognition that the gesture is powerful and must be used with care.

\section{A partner of language}

Pointing is sometimes complete on its own - a wordless command, request, greeting, or tip. But more often points come partnered with words and often those words are demonstratives (e.g., Bühler, 1934/1990; Diessel, 1999; Dixon, 2003; Peeters et al., 2021). This class of words- 
which includes this, that, here, there, these, and those in English—in many cases require a pointing gesture or other visual demonstration to make sense, hence the term. "I'll have this one," said pointing to a full pastry case, is incomplete without a gesture that specifies which one. Some researchers have thus characterized gesture as an "obligatory" partner to demonstratives (Levelt et al., 1985; De Ruiter \& Wilkins, 1998; see discussion in Lücking et al., 2015). This overstates the case, however: This and that can be used without a pointing gesture as long as the referent is salient enough for other reasons (Clark et al., 1983; Talmy, 2017). When a man walks into a bar in a head-turning costume, one can refer to him as "that guy," with no point needed. Nonetheless, it is broadly agreed that demonstratives produced along with pointing — sometimes termed "gestural" uses of demonstratives (e.g., Fillmore, 1982)—are more basic than demonstratives produced without pointing.

When demonstratives and pointing gestures join forces, they form a special type of utterance (Cooperrider, 2016). Speakers only produce a co-demonstrative point when they are confident their gesture can single out the intended target. Thus when speakers are farther from a target, they may continue to point but stop supplementing those points with demonstratives (Bangerter, 2004); and when people have a laser pointer - enabling them to single out a target at any distance - they supplement their points with demonstratives all the more (Cooperrider, 2016). There is also evidence that speakers produce co-demonstrative points with a greater degree of arm extension and hold them for a longer time; they may be putting more effort into these gestures because they are communicatively important (Cooperrider et al., 2021).

The association between pointing and demonstratives is all the more interesting in light of certain properties of demonstratives. For one, this word class appears to be found in every human language (Diessel, 1999; Himmelmann, 1996). (This may not sound impressive, but not 
all languages have adverbs or even adjectives [Evans \& Levinson, 2009]). Demonstratives are also among children's first words (Clark \& Sengul, 1978; Diessel, 2006). And, most remarkably, demonstratives appear to be especially ancient. This is inferred from the fact that they cannot be traced to earlier words, that their etymologies cannot be reconstructed (Diessel, 2006) ${ }^{4}$. No other word class boasts this last property_indeed, even the most workaday function words usually have discernible roots. For example, the can be traced back to an earlier form-the demonstrative that, in fact. This un-traceability suggests that demonstratives may have been present at the very first stirrings of human language; and, if they were, it was likely along with their steadfast partner, pointing.

Pointing partners with other word classes and phrase types as well, of course. As mentioned, it often joins with personal pronouns like I and you (Cooperrider, 2014; Fenlon et al., 2019); it also often partners with time words like now (Cooperrider et al., 2014). An interesting question is whether, in pointing-word combinations, the point conveys information that complements the information in speech or that echoes it. Though pointing can do either, studies suggest it tends to echo what is in speech—to go "hand in hand" with it (De Ruiter et al., 2012; So et al., 2009).

\section{A part of language}

Outside of discussions of demonstratives, there is not much mention of pointing in linguistics textbooks. The gesture rarely attracts comment in descriptive grammars or dictionaries. Spoken language linguists view pointing - like other gestures, facials signals, and

\footnotetext{
${ }^{4}$ The claim that demonstratives cannot be traced to earlier words has not gone unchallenged. Copeland (2000), for example, proposes that the Tarahumara demonstrative includes a root for 'hand,' and, accordingly, he describes the form as "a lexicalized manual gesture."
} 
vocal modulations - as essentially outside of language, as so-called paralanguage. With sign languages, however, the situation is different: Pointing pervades signed communication, and serves many of the functions served in spoken languages by pronouns, demonstratives, locatives, and other basic word classes. Personal pronouns — words like I, you, they —have attracted particular attention; in sign languages, these are produced as points to the signer's own chest, to the addressee, or to a third party (e.g., Friedman, 1975). Debate persists about whether these should be treated as analogous to spoken language pronouns or rather as "mere" pointing gestures (e.g., Cormier et al., 2013; Johnston, 2013b; Meier \& Lillo-Martin, 2013; Pizzuto \& Capobianco, 2008). On the one hand, speakers also gesture toward themselves, their addressees, and to others when referring to $I, y o u$, and they; on the other, signers' points are more rigidly conventionalized than gesturers' points and thus appear to be more word-like (e.g., Fenlon et al., 2019). There are several other arguments for the pronoun-like status of person points (Meier \& Lillo-Martin, 2013). One influential but controversial line of evidence comes from child development: Young signers occasionally show pointing reversals—indicating the addressee when they seem to mean $I$, or themselves when they seem to mean you-much as young speakers sometimes confuse these pronouns (Petitto, 1987; but see, e.g., Morgenstern et al., 2016).

Beyond points to persons, pointing signs are used in a range of other ways. One related use is to anchor reference to non-present third parties (e.g., Barberà \& Zwets, 2013). If one wants to tell a story about two characters, one might start by pointing to empty space on the left and then right to assign a character to each location; later, one can refer back to those characters by pointing to their assigned locations (e.g., Perniss \& Özyürek, 2015), or use the locations to show actions that are directed toward those characters (e.g., Schembri et al., 2018). Sign languages 
also use points for locative (e.g., Fenlon et al., 2013) and demonstrative functions (e.g.,

McBurney, 2002). Importantly, such points differ from spoken language locatives and demonstratives in at least one respect. Spoken languages make categorical distinctions in their locatives (near, far) and demonstratives (this, that). But when signers point, there are no such distinctions - they point to a continuous range of locations.

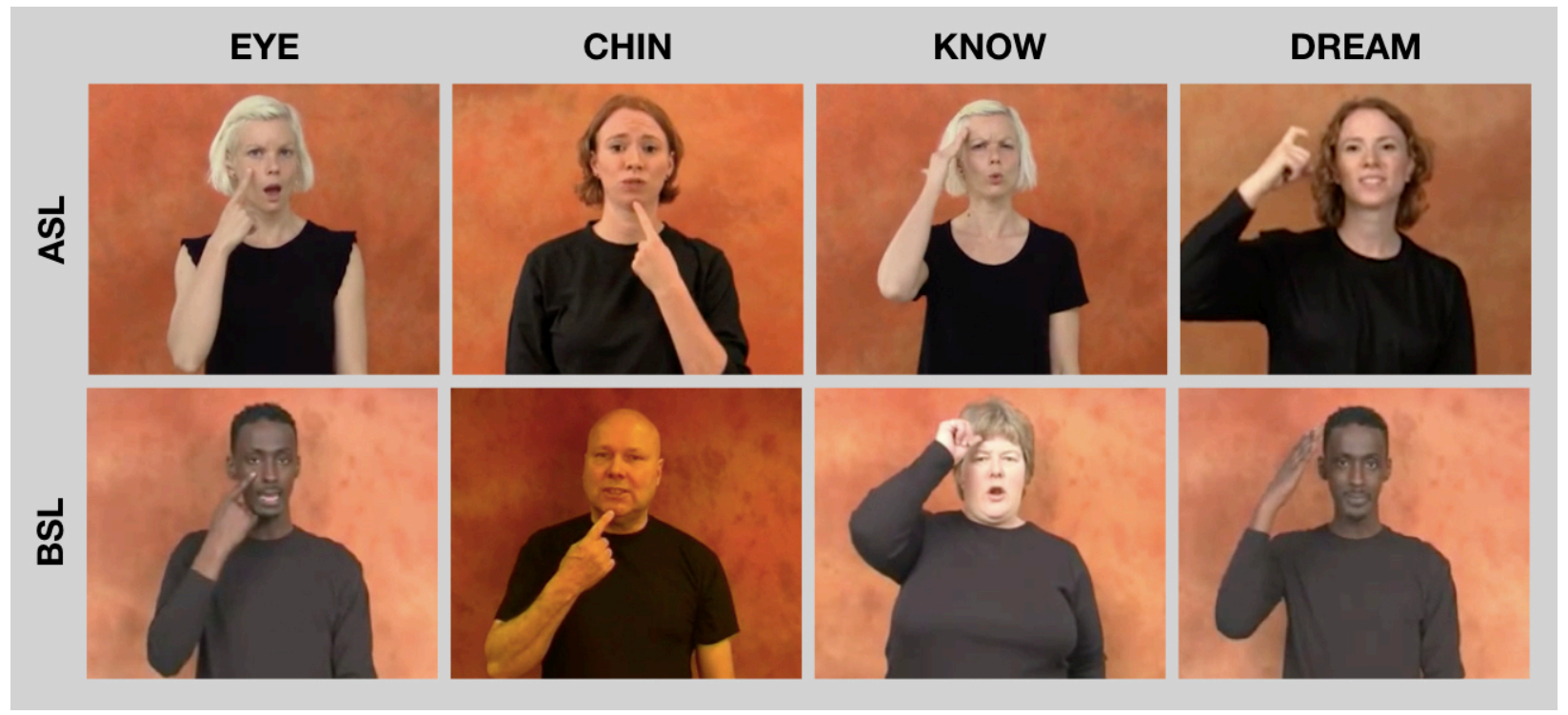

Fig. 4. Stills from a sampling of lexical signs in American Sign Language (ASL; top) and British Sign Language (BSL; bottom) that involve pointing. Body-part terms such as EYE and CHIN commonly involve a point, sometimes with the motion reduplicated. Verbs that are conceptually related to a body part — such as KNOW or DREAM - are often anchored to that part, though they may also involve iconic handshapes or motion patterns (All images: www.spreadthesign.com.)

Pointing also enters abundantly into sign language lexicons. Peruse a sign language dictionary and you'll find a number of signs of all word classes — nouns, verbs, adjectives — that involve pointing in some way (Fig. 4). Body-part terms are a clear case. In ASL, signs including EYE, NOSE, and CHIN are made by index-finger pointing to these features; terms for larger anatomical regions, such as LEG, BACK, and ARM, are produced by pointing with the whole hand 
(Pyers, 2006). These lexical items are often distinguished from more ad hoc pointing gestures by iterating the point. Further, signs for concepts related to body parts are often anchored to that part by pointing (Cooperrider, 2014; Kendon, 1980c). For instance, the signs DREAM or FORGET in several sign languages involve a movement in the vicinity of the head. (The movement and handshape may also add iconic information.) Speakers produce similar gestures (Cooperrider, 2014). Despite the superficial similarities in how speakers and signers point, in many cases pointing signs have become more codified than their counterparts in gesture, and have thus become part of what many would consider language proper.

\section{A subject of art}

Leonardo was by no means the first artist to depict pointing. For centuries before he painted the gesture on his canvases and drew it in his sketchbooks, people had been carving it into stone and weaving it into cloth (Fig. 5). An Egyptian house alter from 1350 BCE portrays a royal couple with three children clambering over them; one, a little girl, points with her index finger while looking back toward her mother. An ancient Zapotec cornerstone shows a figure pointing as a speech bubble rises from his mouth. The Bayeux tapestry, created in England during the $11^{\text {th }}$ century, is rife with pointing fingers; a particularly vivid scene involves a group of men watching - and pointing to-what we now know as Haley's comet (discussed in Cooperrider, 2011). 


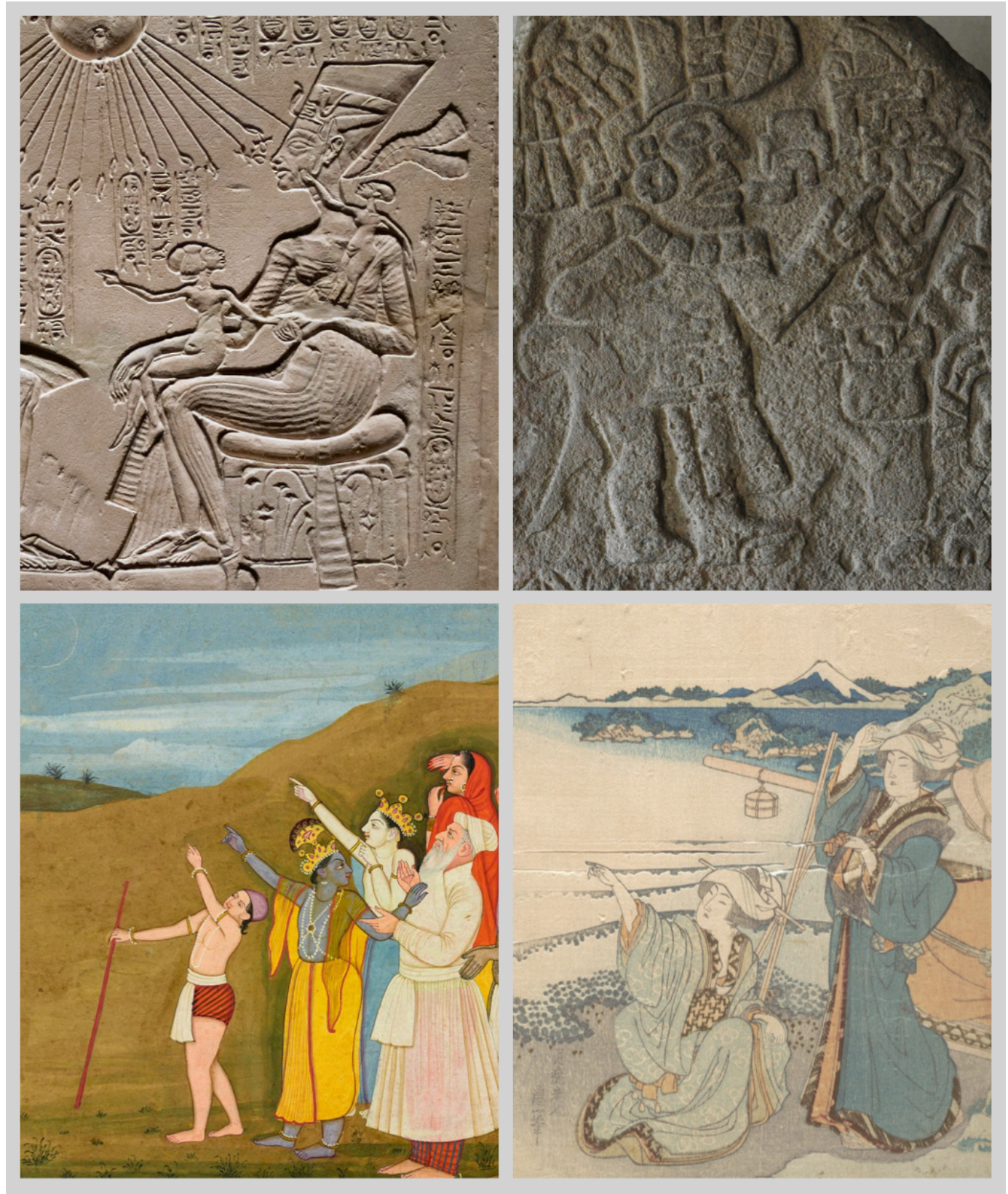

Fig. 5. Representations of pointing from the around the world. Top left: Detail of a limestone house altar from Egypt (c. 1350 BCE) depicting Nefertiti, with one of her daughters on her lap. The daughter is pointing toward her father, the Pharoah Akhenaten, and looking back toward her mother (Image: Flickr user kairoinfo4u). Top right: A Zapotec cornerstone (c. 200 CE) depicting a figure pointing, as a speech bubble arises from the figure's mouth (Image: author). Bottom left: Detail of a watercolor from the state of Himchal Pradesh in India (c. 1775-80) depicting Krishna and his family admiring a solar eclipse (Image: public domain). Bottom right: Detail of an undated woodblock print by the Japanese artist Katsushika Hotusai (1760-1849) titled Two Ladies at Shore; One Pointing (Image: public domain). 
This brief catalogue barely scratches the surface; pointing has been a fixture of representational art for centuries. Several tropes and traditions can be identified. One depicts people pointing to celestial phenomena. The Bayeux tapestry is an example; another is an eighteenth-century watercolor from India, depicting Krishna and his family viewing an eclipse (Fig. 5). In Renaissance art, pointing gestures were legion, especially points directed upward in reference to the divine (Sherman, 2010). (A Spanish saying with a meaning comparable to "when pigs fly" translates as "when Saint John points downward," in reference to John the Baptist.) For centuries, statues have shown a penchant for pointing. Examples include statues of Christopher Columbus in Barcelona, St. Elijah at St. Peters, Moses in New Orleans, and several statues of Lenin pointing to the future (Fig. 6). Alberto Giaccometi's celebrated Man pointing (1947) was sold for more than 140 million USD in 2015, the most expensive sculpture ever. Pointing also figures in the postmodern playfulness of more recent decades. Pointing arm (1990), by Kevin Wolff, depicts an arm reaching around a mirror and pointing to itself. Michelangelo Pistoletto's Donna che indica (1982) shows a woman pointing, her back turned toward the viewer; she is set in a large stainless-steel panel—-the effect is that she points to whatever or whoever is around her. 


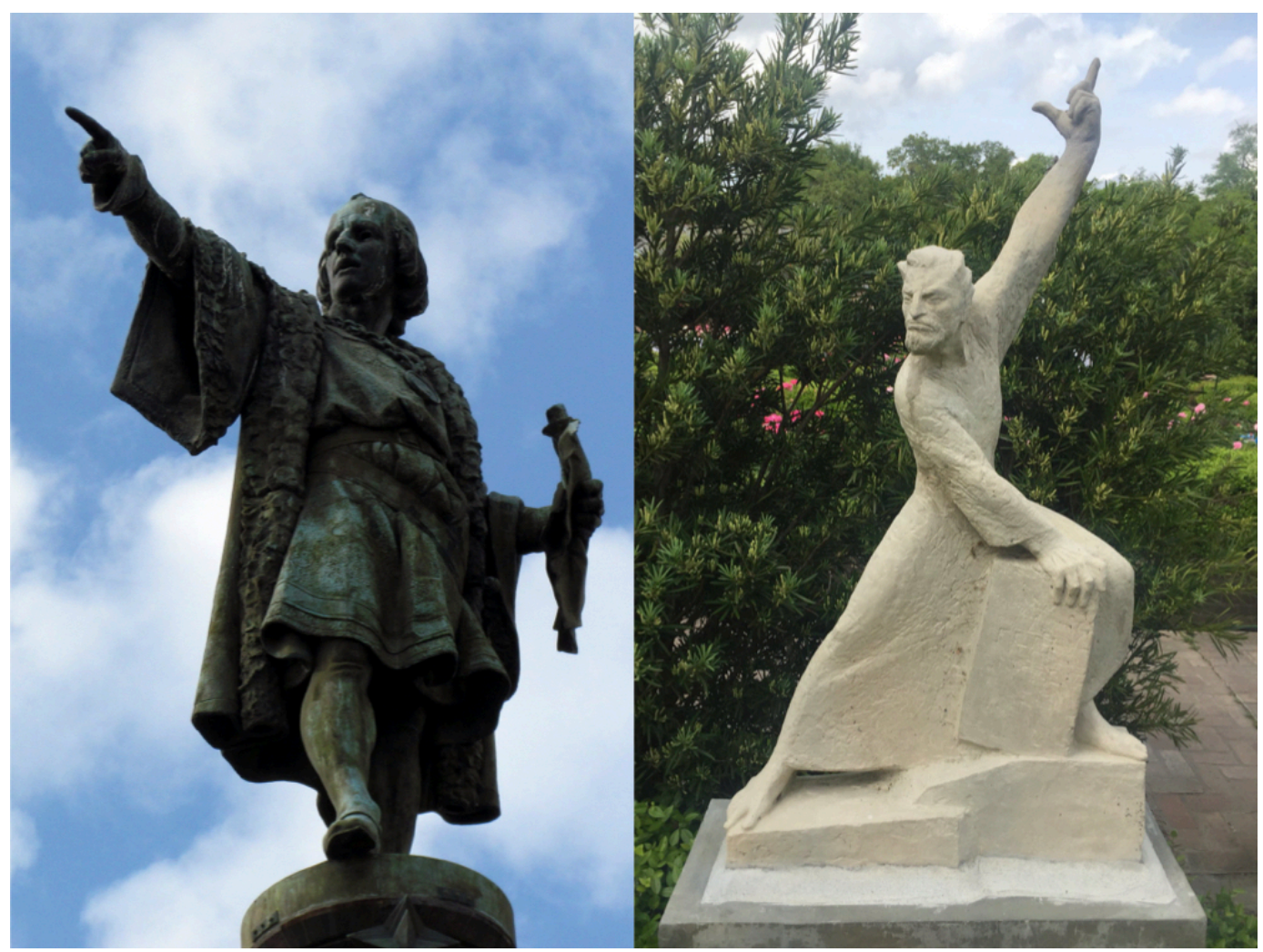

Fig. 6. Examples of statues pointing. Left: The Monumento a Colón in Barcelona, Spain. The statue depicts Christopher Columbus pointing east, perhaps toward his birth city of Genoa, Italy (Image: Flickr user David Berkowitz). Right: A statue of Moses in the New Orleans botanical gardens. The figure clutches a tablet in one hand and, with the other, points toward the divine (Image: Jordan Davison).

Why is pointing — and index-finger pointing in particular — so common in art? Even allowing that it is one of our most commonly used gestures, it seems unexpectedly pervasive. One reason may be that it is one of few gestures that can be readily recognized in static form. Gombrich (1966, p. 395) wrote that "because art arrests movement... [it is] restricted in the gestures it can show unambiguously." He added: "You cannot paint even the shaking of the head we use in the West for 'no'." Nor, he might have added, can you easily paint a head-point. But you can paint an index-finger point with no problem: It has a clear handshape and, in contrast to some gestures, is usually held in place, the arm rising, fixing the target, and pausing at its apex. Another reason for the popularity of pointing is that it can suggest power relations - in 
Gombrich's (1966, p. 394) words, it is “a sign of dominance universally understood." In discussing the puzzling prevalence of pointing in Mesoamerican codices, Olko (2014) also keys on its connotations of command and dominance. In the case of statues, pointing is also a natural choice because it places a figure in conversation with a broader setting. By pointing to a building or monument, or in a certain direction, a statue can command a grander stage than it otherwise would. But perhaps the primary reason pointing abounds in art is the same reason it abounds in life: It is an unmatched tool for orienting attention. Much of what artists do-or aim to do-is orchestrate attention. A pointing gesture is a potent tool for doing precisely that.

\section{A graphical icon}

Beyond its use in particular works of art, pointing has long figured in visual culture as a stylized graphical device. In such uses, pointing is often carried out by disembodied handsmore or less detailed - that float on paper, stone, or screen. For centuries in Europe, beginning at least as early as the $12^{\text {th }}$ century, pointing pervaded manuscripts in the form of the manicule-a term from the Latin word for "little hand" (Sherman, 2010). Manicules were small drawings of hands, usually in the margins, with their index fingers extending into the text to mark noteworthy passages (Fig. 7). 


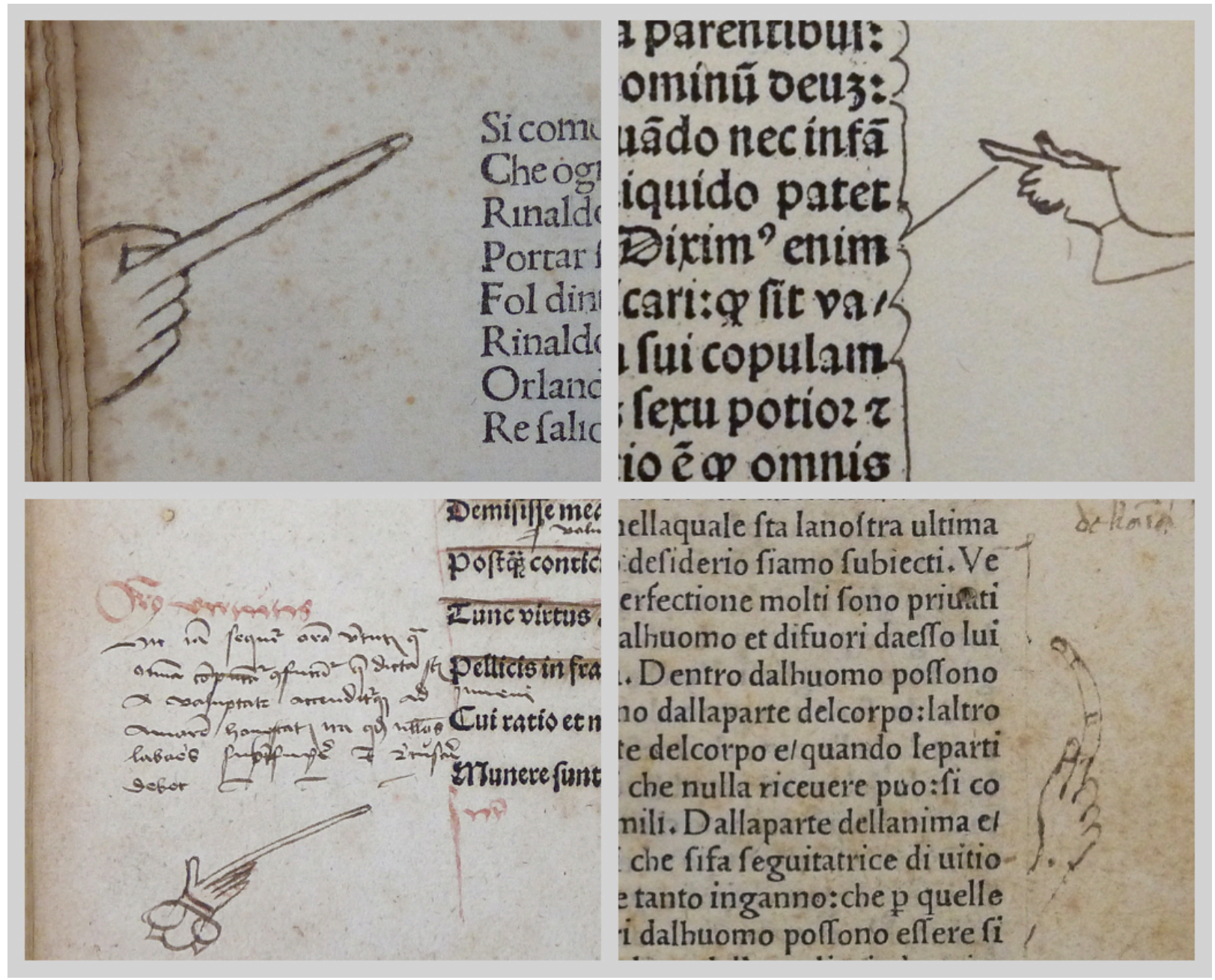

Fig. 7. Examples of manicules — small pointing hands — drawn in the margins of books (All images: Flickr user POP [Provenance Online Project]). Manicules were among the most common forms of marginalia for several centuries in Europe; they were often anatomically improbable and sometimes ornate.

These drawings were often fanciful, bordering on nightmarish: Some had creepily long index fingers, too many fingers, or fingers twisting in anatomically impossible ways. Others took the form of hands emerging from the bodies of beasts; some were not hands at all, but other human or non-human appendages (Houston, 2013; Sherman, 2010). Beginning in the late 1400's, stylized hands also served as printers' marks (Sherman, 2010). These were not merely an occasional adornment: Sherman (2010) writes that between the 12 and $18^{\text {th }}$ centuries, manicules 
"may have been the most common symbol produced both by and for readers in the margins of manuscripts and printed books" (p. 29).

Manicules — in the more general sense of disembodied hands - have also long been used in signage and print (McPharlin, 1942). At some point, they were overtaken by the graphically simpler arrow. However, they can still be seen wherever old-timey style is visually referenced. One context in which such disembodied hands still appear is on fingerposts - those multi-armed road and trail signs that signal the direction and distance of various landmarks. Another is grave markers, which show hands pointing up or, more rarely, down. By some accounts, the upwardpointing version represents "the hope of heaven," whereas the downward-pointing version represents "God reaching down for the soul" and is associated with untimely death (Powell, 2018). Whether in books, signs, or grave-markers, manicules are now rarely used in earnest. Some claim they became so widespread that the public grew weary of them (Houston, 2013).

People today are perhaps most likely to encounter disembodied pointing hands on their screens. Early versions of the desktop cursor depicted a pixelated pointing gesture, instead of an arrow (Sherman, 2010). (Cursors are also called "pointers," and in some interfaces the cursor converts to a gloved, index-finger pointing hand when hovering over a clickable object.) Currently, the pre-eminent use of pointing icons may be emoji, which are widely used in text messaging and social media. Pointing emoji have been around since 1991 and are available in four directions - pointing up, down, left, and right (Gawne \& McCulloch, 2019). According to Gawne and McCulloch (2019), a common use of them is along with the demonstrative this, when trying to direct attention to a post above or below. Given the pervasiveness of pointing icons to date, it's a safe bet that—whatever graphical environments come next—-they will also feature disembodied, pointing hands in some form. 


\section{A cognitive prop}

Pointing is a powerful tool for directing attention —including the pointer's own attention. In Japan, when a train enters a station, an employee may hop out and begin a crisp routine of shisa kanko ("point and call") (Richarz, 2017). With no particular audience in mind, the worker proceeds through a series of safety checks, pointing to different targets in the process. Similar pointing-for-no-one behaviors can be observed in very young children. One study conducted a hide-and-seek task with 18- to 24-month-old children (DeLoache et al., 1985). The experimenter hid a toy while the child watched; a timer was set, and the child was asked to wait. During the four-minute interval before the children could retrieve the toy, they talked about the to-beremembered location, looked at it, and pointed to it. Similar "mnemonic" uses of pointing have been observed in 2- to 4-year-old children (Delgado et al., 2011). Informal observations of this type of "private pointing" go back decades, and have been used to argue that, when pointing first emerges in children, it emerges as a self-orienting behavior rather than as a social one (e.g., Lempert \& Kinsbourne, 1985).

One domain in which private pointing is especially pronounced is counting. One study had adults look at photos of haphazardly strewn change - quarters, dimes, and nickels — and count it as quickly as possible. On half the trials, subjects were allowed use their hands to point to the photo and on the other half were not. When the subjects could point, they counted faster and made fewer errors (Kirsh, 1995). Spontaneous pointing behaviors can also be observed in simpler counting tasks, beginning at a young age (Gordon et al., 2019; Saxe \& Kaplan, 1981). And this pointing has benefits: Four-year-olds were better at counting arrays of chips when they could touch or point to them-or, interestingly, when a puppet touched or pointed to the chips on 
their behalf (Alibali \& DiRusso, 1999). Adults also point spontaneously in simple array-counting tasks and benefit from doing so; and, if prohibited from pointing, they turn to nodding instead (Carlson et al., 2007). Even chimpanzees spontaneously point when engaging in counting-like behavior, suggesting that the urge to use the hands to orient one's own attention is deep-seated in our lineage (Boysen et al., 1995).

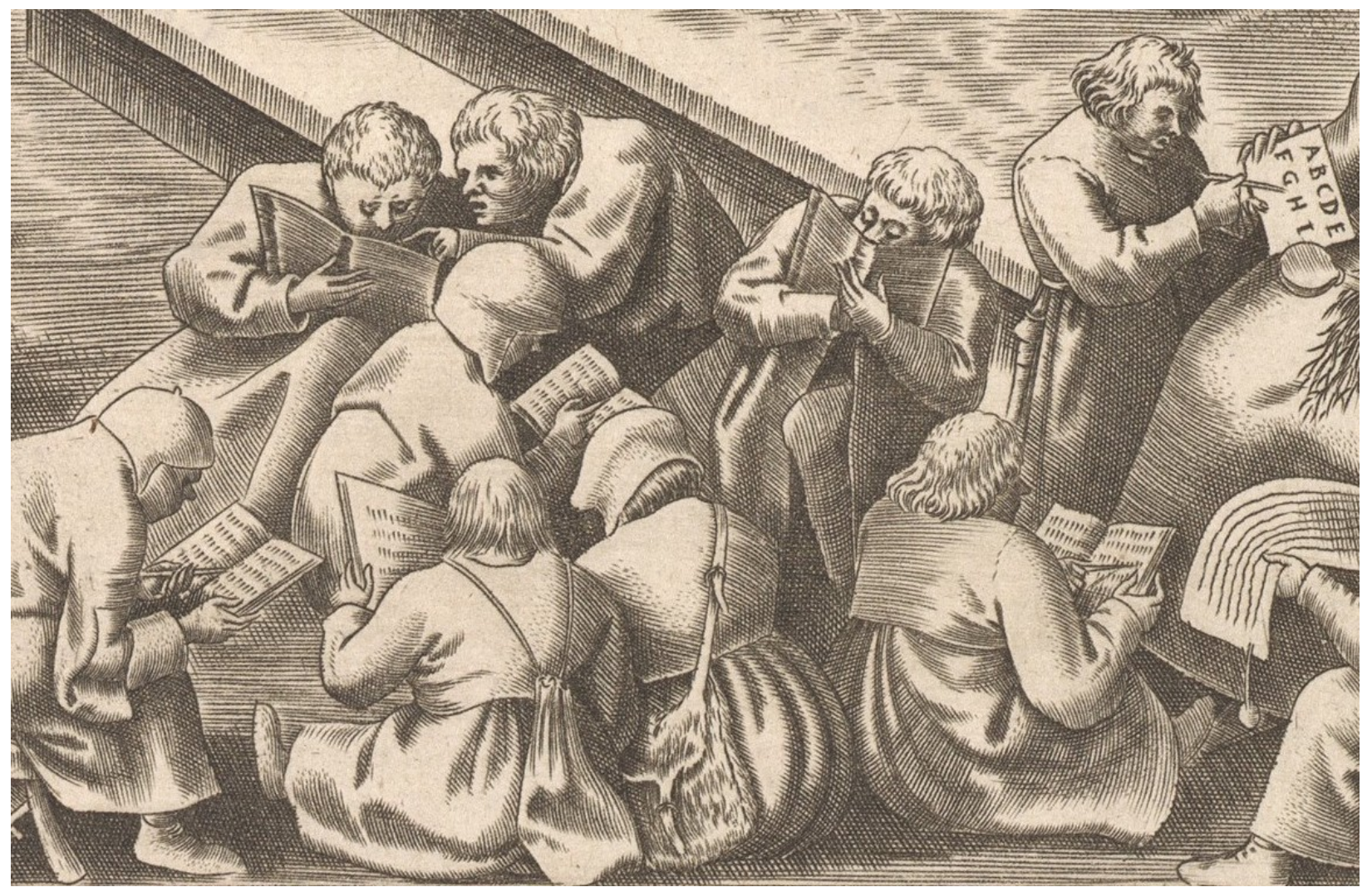

Fig. 8. Detail of Temperance (c. 1559-60), a print by Philips Galle, after Pieter Bruegel the Elder (Image: public domain). A group of men are huddled together, absorbed in books. Several are pointing to their texts with writing implements or fingers, in an apparently self-directed manner.

Pointing-for-self may also be observed during reading. Children often use their index fingers to point to or trace words as they sound them out, though systematic studies are lacking. Adults sometimes do this as well. The print Temperance (1559-1560), after Pieter Bruegel the Elder, depicts a group of figures, hunched over inscriptions, using fingers or tools to follow the 
words (Fig. 8). In the Jewish tradition, readers of the Torah use ritual pointers called yads, which often have a tiny pointing hand at their tip; originally at least, these served to keep greasy fingers off fragile manuscripts. Some speed-reading techniques involve rapidly running the hand under the text while one "reads" it, a practice sometimes called "hand pacing."

Claims of speed-reading proponents notwithstanding, the possible benefits of pointingfor-self during reading are unknown. Seeing others point, however, appears to be helpful. Many educators emphasize the importance of various "print referencing" strategies, including pointing, in getting children to attend to text (Justice \& Ezell, 2004), and the benefits of these practices have been observed in a randomized-controlled trial (Piasta et al., 2012). And tracing graphical materials with one's own index finger appears to have a number of benefits. It has been shown to boost learning in studies of students understand temperature graphs (Agostinho et al., 2015), geometry (Hu et al., 2015), the water cycle (Tang et al., 2019), and the human heart (Korbach et al., 2020). One study of people with stroke-induced alexia — the inability to read—found that instructing them to trace letters improved their text-copying and reading ability (Seki et al., 1995). A study of people with aphasia — the inability to speak — found that pointing improved their ability to name common objects (Hanlon et al., 1990). Across ages, contexts, and subpopulations, pointing proves to be a handy, helpful, and even rehabilitating cognitive prop.

\section{A developmental milestone}

Babies usually begin to point as they near the end of their first year (e.g., Capirci et al., 2005; Moore et al., 2019). The gesture is one of their earliest communicative acts - usually preceding their first words by some weeks (Carpenter et al., 1998) —and marks a major milestone in their social development. (Other indicating gestures emerge around the same time 
but have not been as widely studied [but see, e.g., Choi et al., 2021; Moreno-Núñez et al., 2020]). One study reported roughly the same timeline for the emergence of pointing in seven very different cultural settings, with children first pointing with their whole hand and then, a bit later, replacing that with index-finger pointing (Liszkowski et al., 2012). What are children doing when they first begin to point? What exactly is it they are trying to communicate? Early studies divided children's first points into those that had an imperative function (a nonverbal "I want that!") and those that had a declarative function (a nonverbal "Isn't that cool!") (Bates et al., 1975). Not only do these two types of points have different functions, they also have different forms. Imperative points tend to be produced with the whole hand, whereas declarative points tend to be produced with an extended index finger (Cochet \& Vauclair, 2010; Grünloh \& Liszkowski, 2015). Many researchers favor a "cognitively rich" interpretation in which these early declarative points reflect the infant's desire to influence others' attention, thoughts, and feelings (Tomasello et al., 2007; see Leavens, 2012 for critical discussion). Some further suggest children may have an information-gathering aim, as pointing often results in a caregiver providing additional information about whatever is pointed to (Begus \& Southgate, 2012; Southgate et al., 2007).

The basic timeline surrounding the emergence of pointing is now established, but the deeper origins of this milestone remain mysterious. A variety of accounts have been proposed. One idea is that pointing is "ritualized" from reaching (Vygotsky, 1988; see also Wundt, 1973). On this account, babies will sometimes try to grab objects that are out of reach; over time, they realize that adults often supply the out-of-reach object anyway; in this way, they learn to outstretch their arms toward a desired object— that is, to point. Recent work offers some support for this view by showing that 8-month old children are more likely to reach toward unreachable 
objects when adults are present than when they are not (Ramenzoni \& Liszkowski, 2016).

Another common proposal is that pointing is learned by imitating adults. A recent training study cast doubt on this possibility, however, showing that exposing pre-pointing infants to a veritable pointing bonanza did not change when they acquired the gesture (Matthews et al., 2012). A third idea is that pointing begins as a spontaneous orienting behavior, a way of guiding one's own attention, and is only later co-opted for communication (e.g., Carpendale \& Carpendale, 2010; Lempert \& Kinsbourne, 1985). A fourth proposal, compatible with others, is that pointing originates in touch (e.g., Kettner \& Carpendale, 2018). Long before pointing in communicative situations, infants extend their index fingers (Lock et al., 1994; Masataka, 2003; Shinn, 1900), often in the context of exploring objects with their fingertips ${ }^{5}$. Lock et al. (1994) describe this behavior as points "slipping out" (in the terminology used here, it is another form of pseudopointing). A recent set of studies found evidence that pointing has the character of simulated touch even in adults (O'Madagain et al., 2019). When pointing to a sticker on the vertical face of a three-dimensional box, for example, people rotate their wrists as though trying touch the sticker and rather than merely indicate its direction.

Whatever its origins, the onset of pointing offers a glimpse of what is coming next. It is possible to predict the words that will soon enter a child's vocabulary by looking at which objects the child is pointing to (Iverson \& Goldin-Meadow, 2005). Moreover, the age when children first point to an entity while simultaneously offering a spoken label for it (e.g., a point at a dog with "dog") predicts the age at which they will produce noun-plus-determiner combinations in speech (e.g., "the dog”) (Cartmill et al., 2014). A meta-analysis of 25 studies on pointing and child development corroborated such tight links between pointing proclivities and

\footnotetext{
${ }^{5}$ Similar index-finger-as-probe behaviors have also been described in chimpanzees (e.g., InoueNakamura \& Matsuzawa, 1997; Kellogg \& Kellogg, 1933, p. 125)
} 
linguistic abilities (Colonnesi et al., 2010). Interestingly, these correlations held only for declarative pointing, not imperative (see also Salo et al., 2019). One interpretation of such links is that pointing savvy reflects general communication savvy, such that kids who are good at pointing also tend to be good at talking. But it's also possible that pointing guides language learning in a more direct way (Goldin-Meadow et al., 2007). Caregivers often respond to their children's points by offering labels or explanations (Lucca \& Wilbourn, 2018), and evidence suggests that "fact-finding" may be part of what motivates children to point in the first place (Lucca \& Wilbourn, 2019). Put together, such observations support the conclusion that pointing is not merely a milestone but, as one researcher put it, "the royal road to language" (Butterworth, 2003).

\section{A diagnostic window}

Because pointing is such a basic communicative act, it often serves as a diagnostic window. It's an outward sign of what is going on inside the mind and body — an index to abilities, proclivities, or deficits we might not otherwise be able to see. Since pointing emerges within a relatively narrow window in typically developing infants — usually between 10 and 14 months - its absence or delay can signal trouble ahead. One study found that children that only point with the whole hand, not the index finger, by 12 months are at greater risk for primary language delay at two years (Lüke, Rohlfing, et al., 2017). Another found that children with primary language delay point less at one year of age and more at two years of age, compared to their typically developing peers (Lüke, Ritterfield, et al., 2017). (Typically developing children point less by age two, as speech overtakes gesture [e.g., Lock et al., 1994]). Among infants with 
early brain damage, pointing behavior at 18 months predicts whether a child's vocabulary will fall within normal ranges in the second year of life (Sauer et al., 2010).

Pointing can also serve as a diagnostic of more general cognitive profiles beyond communicative competence. Several studies have found that children with autistic spectrum disorder (ASD) fail to understand or produce declarative points (Baron-Cohen, 1989; Goodhart \& Baron-Cohen, 1993; for reviews, see Sparaci, 2013; Manwaring et al., 2018). The precise reasons for this failure remain debated and, importantly, some children with ASD do produce points (Manwaring et al., 2018). Children with Williams syndrome also show deficits in producing and understanding points, despite boasting superior vocabulary (Laing et al., 2002). In fact, in an inversion of the typical developmental sequence, children with Williams syndrome usually talk before they point, by an average of six months (Mervis \& Becerra, 2007).

Pointing is also used as a diagnostic window in adults. It offers a basic form of experimental response in a variety of psychological paradigms; and, as a simple bodily coordination task, it offers a window into motor control (Jones \& Lederman, 2006) and a variety of neurological issues (e.g., Berti \& Frassinetti, 2000). In the 1920s researchers uncovered a class of deficits—-sometimes called "pointing disorders"- that reflect issues with the neural machinery of body knowledge. The neurologist Arnold Pick identified a pair of patients who were able to name parts of their own body when asked, but, mysteriously, were unable to point to them—a disorder that would be classed as "autotopagnosia" (Felician et al., 2003). It was later found that this inability may also extend to the bodies of others ("heterotopagnosia"), and that the inability to point to others' body parts can occur despite intact ability to point to one's own (Degos et al., 1997). The presentation of this disorder is puzzlingly specific. One patient, a 41year old man, scored almost perfectly in his ability to name and point to his own body parts; he 
also had no trouble naming the same body parts of the examiner, and he was even able to grasp the examiner's body parts if asked. Yet he was completely unable to point to them (Degos et al., 1997). (A common behavior during examinations of heterotopagnosic patients is "selfreferencing," in which patients respond to requests to point to an examiner by pointing instead to themselves, sometimes with a comment like "your nose... is here... behind my nose" [Cleret de Langavant et al., 2009, p. 1749]). Subsequent studies have found that heterotopagnosics can often point to more abstract bodies: They are slightly better at pointing to photographs than actual people, better still at pointing to dolls, and near perfect at pointing to line drawings (Cleret de Langavant et al., 2009). A possible explanation for this deficit- though far from a settled one- is that it stems from an inability to see another's body as both subject and object (Cleret de Langavant et al., 2012; see also Tallis, 2010).

Because pointing is basic way of indicating direction, it is widely used as an index of spatial awareness (e.g., Nazareth et al., 2019). Lewis (1976), for instance, used a simple pointing task to explore dead-reckoning ability in Australian Aboriginals. He had five Aboriginal men point to distant landmarks or cardinal directions while he stood behind them and checked their accuracy with a compass. The average deviation across 34 targets tested was a mere 14 degrees. A later cross-cultural comparison revealed that the accuracy of Europeans' points pales in comparison (Levinson, 2003). A more recent study found that, when asked to point to cardinal directions, all fourteen members of an Australian Aboriginal community were correct to within 10 degrees; of the fourteen Stanford University affiliates tested for comparison, only a third were correct to within 30 (Boroditsky \& Gaby, 2010). Even during storytelling, it appears that when Australian Aboriginals point somewhere, they point accurately (Haviland, 1993). Impressionistically, this contrasts with how many Anglo-Europeans point in conversation. As 
Schegloff (1984) observed, when American English speakers point to non-visible locations, they are not necessarily pointing accurately, as when "two people referring to the same place... point in different directions" (p. 280). Throughout the lifespan, whether one points - as well as when, how, and where - offers vital clues to what is going on in one's mind and brain.

\section{A cross-species litmus test}

Pointing is frequently trumpeted as a uniquely human communicative behavior, one that does not come naturally even to our closest primate cousins (Povinelli et al., 2003; Tallis, 2010; Tomasello, 2006). This uniqueness claim has not gone unchallenged, however. One study reported the following field observations of bonobos in Zaire:

"Noises are heard coming from the vegetation. A young male swings from a branch and leaps into a tree... He emits sharp calls, which are answered by other individuals who are not visible. He points - with his right arm stretched out and his hand half closed except for his index and ring fingers - to the position of the two groups of camouflaged observers who are in the undergrowth."

(Veà \& Sabater-Pi, 1998, p. 289)

For years this was the only account of pointing by a primate in the wild. Other possible cases have since come to light, produced by bonobos when attempting to initiate genital rubbing (Douglas \& Moscovice, 2015) and by chimpanzees when reaching with an open hand toward desired objects (Hobaiter et al., 2014). The researchers reporting these latter observations admit, however, that, even if it is attested, chimpanzee pointing in the wild appears to be "vanishingly rare" (Hobaiter et al., 2014, p. 84) and that the interpretation of the few documented cases remains fraught. Chimpanzees and bonobos do seem to regularly direct each other's attention using other signals, such as "directed scratching" (Pika \& Mitani, 2006) and beckoning (Genty \& Zuberbühler, 2014). There is thus no question that primates in the wild behave in ways that steer 
attention; what remains debated is whether they try to steer attention in the overt ways that humans do and whether they do this by pointing.

While chimpanzee pointing in the wild remains debatable, the fact that they point in captivity is well established. Such pointing has nonetheless usually been thought marginalimperative rather than declarative, produced only for humans and never for other apes, and often involving the full hand (except where cage mesh induces finger extension) (for a critical review, see Leavens, 2012). A counterpoint to these claims, as Leavens (2012) notes, is that apes trained to use signs from a natural human language do point declaratively and with the index finger (see Gardner \& Gardner, 1969; Lyn et al., 2011). Recent results also suggest that captive chimpanzees use pointing as flexible signal, raising their arms higher to point to further targets (Gonseth et al., 2017; Roberts et al., 2014)—much as humans do (e.g., Mesh, 2021)—and adapting their gestures in other ways to fit the communicative context (Tauzin et al., 2020). In short, apes do point—flexibly and even declaratively_provided sufficient human scaffolding and interaction, but they can hardly be said to have a natural proclivity for pointing.

As debates about chimpanzees continue, research on animal pointing has broadened out considerably. Recent studies have examined the putative production of pointing (and related attention-directing gestures) in mangabeys, dogs, horses, dolphins, and magpies, among others (Krause et al., 2018). Such behaviors do not look like canonical index finger pointing, of course - many of these animals do not have fingers. Rather, they are other bodily acts that seem intended to direct attention, such as poking a rostrum (in dolphins; Xitco et al., 2001) or projecting a beak (in magpies; Kaplan, 2011). (Also discussed in this context are other forms of indicating, such as proffering food [e.g., in ravens; Pika \& Bugnyar, 2011]). In some cases, these pointing-like movements include additional features that would seem to mark them as signals 
rather than as practical actions, much as non-manual pointing in humans involves "signal establishing" features. For instance, during collaborative hunting with eels, grouper fish signal the location of hidden prey by orienting their bodies vertically over the hiding spot and producing headshakes (Bshary et al., 2006; Vail et al., 2013). But are these flexibly deployed signals? Might they reflect the signaler's arousal rather than any communicative intention? These and other difficult questions leave skeptics quick to dismiss pointing-like behaviors in animals as "merely instrumental" (see Kaplan, 2011).

A parallel branch of research focuses, not on whether animals naturally point for each other, but on whether they understand human pointing (Krause et al., 2018). The question is more experimentally tractable, permitting tidy designs and clever manipulations; it thus provides a litmus test that can be applied across diverse taxa. Most studies on this question use a variant of the "object choice paradigm" (e.g., Hare et al., 1998). In this set-up, an experimenter tries to cue an animal to the presence of food in one of two locations (e.g., buckets on right and left) by pointing. If the animal takes the cue rather than guesses randomly, this suggests an understanding of the gesture's function. An influential early finding using this method was that domestic dogs tend to take the cue, but chimpanzees do not (Hare \& Tomasello, 2005). This suggested that dogs may have evolved to understand pointing over their millennia-long partnership with Homo sapiens. Work since has offered a more mixed picture. Some researchers have presented evidence that interactions over an animal's lifespan are more critical than genetic inheritance: It was reported that wolves who have interacted regularly with humans understand pointing, while domestic dogs who have not interacted with humans do not (Udell et al., 2008). Two more recent studies, however, have vindicated the idea that dogs have an evolved ability to understand human cues such as pointing: one showed that, already at 5-18 weeks, domestic dog pups outperform 
wolf pups at reading such cues (Salomons et al., 2021); another found, in a large sample of 8week-old dog pups, that sensitivity to human pointing is emerges very early and is highly heritable (Bray et al., 2021).

Beyond primates and dogs, the issue has now been examined in capuchins, sea lions, elephants, bats, pigs, goats, cats and other species, with many studies reporting some degree of pointing understanding (Krause et al., 2018). Importantly, even species that succeed on this task do not necessarily succeed at levels comparable to human adults. On a standard object choicetask with two options, chance performance is 50\%; the much-trumpeted success of African Elephants, for example, consisted of correct responses on 68\% of trials (Smet \& Byrne, 2013). From this still-expanding and sometimes conflicting literature on animal pointing, a few generalizations emerge. Interaction with humans over the lifespan improves understanding of human pointing (Krause et al., 2018), and domestication processes seem to have given some species a heightened sensitivity to human gestures. Further, animals from diverse habitats and taxa, and with widely different body-plans, behave in ways that steer the attention of their conspecifics; the thorniest question is whether they direct attention with the same kinds of motives and intentions that humans do. In sum, the refrain that "animals don't point" is too coarse. But there is little question that there is something human about pointingcharacteristically human if not uniquely so.

\section{An evolutionary stepping-stone}

Several scholars have cast pointing in a starring role in the emergence of language. This casting decision makes sense in light of some of the ways of looking at pointing already considered. If pointing is a semiotic primitive, the "simplest of the simplest" way of meaning 
something, it was probably present right at the beginning. If the words most closely associated with pointing — demonstratives — are impossible to trace to earlier words, perhaps both pointing and demonstratives belong to the oldest bedrock of human language (e.g., Diessel, 2006). If pointing is among the first forms of communication used as a child develops, maybe it was among the first forms of communication used as humankind developed (e.g., Meguerditchian et al., 2011). If our closest cousins only sort of point — that is, under the right circumstances, but mostly with brutish motives - perhaps it was the development of full-blown declarative pointing that marked the separation of man from beast (e.g., Tomasello, 2008). Semiotically simple, apparently ancient, developmentally privileged, distinctively human — why not then, suppose pointing is also evolutionarily primordial?

The idea that pointing served as an evolutionary stepping-stone is tied up with the more general notion that language began in the hands. This "gesture first" idea has deep roots (e.g., Hewes, 1973; for discussion, see Kendon, 2017) and remains popular today (Arbib et al., 2008; Corballis, 2008; Tomasello, 2008), though it has hardly gone unchallenged (e.g., Levelt, 2004). Beyond the intuitive "gesture is primitive" rationale supporting such accounts, a widely bruited argument is that great apes, our closest cousins, use gestures more flexibly than vocalizations (e.g., Pollick \& de Waal, 2007). An emerging alternative to gesture-first theories is what might be called "multimodal-all-along" views (e.g., Fröhlich et al., 2019; Kendon, 2017). Some in this latter camp deny a privileged role for gesture over speech, but nonetheless give pointing pride of place among the earliest "strata" of multimodal language (e.g., Levinson \& Holler, 2014).

Among gesture-first accounts, the role of pointing varies. Some do not specify which particular types of gestures came first (e.g., Corballis, 2008). Others stress the importance of pantomime - that is, imitations of actions produced without speech (Arbib et al., 2008; Mallery, 
1882; Zlatev et al., 2020). A few scholars, however, have granted pointing special primordial status (e.g., Hewes, 1996). Tran Duc Thao proposed that pointing evolved in the context of hunting on the open savannahs of Africa, and that language followed from it (Thao, 1984; discussed in Hewes, 1981). More recently, Tomasello (2008) has argued that pointing was "the primordial form of uniquely human communication" (p. 3). For Tomasello, what is most distinctive about our species is a cooperative mode, and he sees pointing as a basic tool of cooperative communication. Others have outlined detailed accounts of the steady elaboration of human communicative competence, extending from pointing to full-blown grammar (Bejarano, 2011; Rolfe, 1996). Such “pointing first” proposals have occasionally met with skepticism. Bühler (1934/1990) commented, with derisive tone, on the "myth of the deictic origin of language" (p. 100; see Diessel, 2012). By this he meant the idea, popular in his day, that "what is specifically human... begins with the genuine deictic gesture, and the rest inexorably emerges from it" (p. 101). Perhaps the idea seems far-fetched. But as Bühler noted a beat later: "Myths need not be false."

\section{Conclusion}

The cognitive scientist Elizabeth Bates — who, among other contributions, pioneered the study of infant pointing - observed that when you look at something for long enough, you start to see it as having "cosmic importance" (Bates, 1979, p. 33). You start, as William Blake put it, to see the world in a grain of sand. I'm not the first to see a world in pointing. Bates herself perhaps did, as did Tallis (2010), who comments toward the end of his book: "How small the index finger and how great its effect" (p. 143). Pointing may not contain the world, but there is little question it contains multitudes. In it we find a declaration, a command, a question, a reproach, a 
jibe, a citation, a transgression; we have a highlighter, a crystal ball, a spy-hole, and a springboard; we have a gesture that salutes, instructs, offends, and aggresses; we have an act that is proscribed, stylized, and grammaticalized. And though the gesture has been the subject of scrutiny and scholarship for centuries, there remain a number of unsettled questions about how and why it is used (Table 2).

Table 2

\section{Unsettled questions for further research}

Why is pointing so pervasive in humans? When and why is it used instead of speech?

Why is index-finger-extended pointing favored over other forms, at least in WEIRD settings? And why is non-manual pointing (e.g., lip-pointing) more common outside of WEIRD settings?

Why is index-finger pointing considered aggressive? Why is it so widely tabooed?

How do pointing signs and pointing gestures differ?

Why is pointing so commonly represented in art, including in paintings and statues?

Why do children (and sometimes adults) point to text as they read it? Is this behavior helpful?

Why do children point initially? Do such early points emerge out of reaching, touching, or both?

What is the nature of the underlying deficit in autotopagnosia and heterotopagnosia?

If chimpanzees are able to point in the captivity, why do they not point (or not point much) in the wild?

What motives and intentions are involved when diverse animal species produce pointing-like behaviors? What inferences do they make when they see human pointing?

What was the role of pointing — versus pantomime and other iconic gestures - in the evolution of language? 
Another thinker who saw a lot in pointing was Leonardo. The puzzle of what drew him to the gesture is unresolved and probably unresolvable. Perhaps he was not interested in pointing per se. I would venture instead that he was interested in attention, and that his interest in pointing may have been just a natural extension of this broader, deeper fascination. He was intrigued with the nature, dynamics, and mysteries of human looking, particularly its anatomy (e.g., the workings of the human eye) and geometry (e.g., issues of perspective) (Isaacson, 2017). As a painter, he understood his task was to capture and guide the attention of his audience. He must have recognized that, in art as in life, pointing is an unmatched means of doing just that. No wonder he was "mesmerized” (Isaacson, 2017, p. 474).

This suggestion about Leonardo may also shed light on the larger puzzle of why generations of scholars, artists, and scientists have been mesmerized by pointing - and have seen it from so many different angles. In short, we are creatures of attention. Today, attention is increasingly described as a major currency of social and cognitive life — an idea reflected in phrases like the "attention economy" and books with titles like The Attention Merchants. This attention-as-resource framing may be new, but the truth behind it is old. Our species' preoccupation with attention — with monitoring, steering, controlling, disguising, and advertising it - is long-standing, deep-seated, and perfectly embodied in the pointing gesture. It's a preoccupation - and a gesture - that emerges in the first year of life and is likely as ancient as language itself.

Ultimately, then, the human pointing gesture is like "a finger pointing to the moon" in the well-known Zen saying. The saying — popularized by Bruce Lee in the 1973 film Enter the Dragon —offers an analogy: the pointing finger is some lesser thing that people focus on instead the greater thing that it points to. In a similar way, though much research has focused on the 
pointing gesture - and on its prototypical form - perhaps more important than the gesture itself is what it indicates: our distinctively human preoccupation with attention. The human pointing gesture - in whatever guise it appears—is a symptom and symbol of this broader fixation. In trying to understand the gesture's ubiquity and multidimensionality, future work might do well to look beyond pointing per se. We might be wise, in other words, to heed the words of Bruce Lee: "Don't concentrate on the finger, or you will miss all that heavenly glory." 


\section{References}

Agostinho, S., Tindall-Ford, S., Ginns, P., Howard, S. J., Leahy, W., \& Paas, F. (2015). Giving learning a helping hand: Finger tracing of temperature graphs on an iPad. Educational Psychology Review, 27(3), 427-443.

Alibali, M. W., \& DiRusso, A. (1999). The function of gesture in learning to count: More than keeping track. Cognitive Development, 14(1), 37-56.

Alibali, M. W., Nathan, M. J., \& Fujimori, Y. (2011). Gestures in the mathematics classroom: What's the point? In N. Stein \& S. Raudenbush (Eds.), Developmental Cognitive Science Goes to School (pp. 219-234). Routledge.

Andrén, M. (2010). Children's Gestures from 18 to 30 months. Department of Linguistics and Phonetics, Centre for Languages and Literature, Lund University.

Arbib, M. A., Liebal, K., \& Pika, S. (2008). Primate vocalization, gesture, and the evolution of human language. Current Anthropology, 49(6), 1053-1076.

Astuti, R. (1995). People of the sea: Identity and descent among the Vezo of Madagascar. Cambridge University Press.

Augustine, Saint (1996). Confessions. Harvard University Press.

Bailey, F. (1942). Navaho motor habits. American Anthropologist, 44(2), 210-234.

Bangerter, A. (2004). Using pointing and describing to achieve joint focus of attention in dialogue. Psychological Science, 15, 415-419.

Bangerter, A., \& Oppenheimer, D. M. (2006). Accuracy in detecting referents of pointing gestures unaccompanied by language. Gesture, 6(1), 85-102.

Barberà, G., \& Zwets, M. (2013). Pointing and reference in sign language and spoken language: Anchoring vs. identifying. Sign Language Studies, 13(4), 491-515.

Barnes, R. H. (1973). The rainbow in the representations of inhabitants of the Flores area of Indonesia. Anthropos, 3/4, 611-613.

Baron-Cohen, S. (1989). Perceptual role taking and protodeclarative pointing in autism. British Journal of Developmental Psychology, 7(2), 113-127.

Bates, E. (1979). The emergence of symbols: Cognition and communication in infancy. Academic Press.

Bates, E., Camaioni, L., \& Volterra, V. (1975). The acquisition of performatives prior to speech. Merrill-Palmer Quarterly, 21(3), 205-226. 
Bavelas, J. B., Chovil, N., Lawrie, D. A., \& Wade, A. (1992). Interactive gestures. Discourse Processes, 15, 469-489.

Begus, K., \& Southgate, V. (2012). Infant pointing serves an interrogative function. Developmental Science, 15(5), 611-617.

Behne, T., Liszkowski, U., Carpenter, M., \& Tomasello, M. (2012). Twelve-month-olds' comprehension and production of pointing. British Journal of Developmental Psychology, 30(3), 359-375.

Bejarano, T. (2011). Becoming human: From pointing gestures to syntax. John Benjamins.

Berti, A., \& Frassinetti, F. (2000). When far becomes near: Remapping of space by tool use. Journal of Cognitive Neuroscience, 12(3), 415-420.

Blust, R. (2021). Pointing, rainbows, and the archaeology of mind. Anthropos, 116, 145-161.

Bohn, M., Call, J., \& Tomasello, M. (2015). Communication about absent entities in great apes and human infants. Cognition, 145, 63-72.

Bonvillian, J. D., Ingram, V. L., \& McCleary, B. M. (2009). Observations on the use of manual signs and gestures in the communicative interactions between Native Americans and Spanish explorers of North America: The accounts of Bernal Díaz del Castillo and Álvar Núñez Cabeza de Vaca. Sign Language Studies, 9(2), 132-165.

Borg, E. (2002). Pointing at Jack, talking about Jill: Understanding deferred uses of demonstratives and pronouns. Mind \& Language, 17(5), 489-512.

Boroditsky, L., \& Gaby, A. (2010). Remembrances of times east: Absolute spatial representations of time in an Australian Aboriginal community. Psychological Science, 21(11), 1635-1639.

Boysen, S. T., Berntson, G. G., Shreyer, T. A., \& Hannan, M. B. (1995). Indicating acts during counting by a chimpanzee (Pan troglodytes). Journal of Comparative Psychology, 109, 4751.

Bray, E. E., Gnanadesikan, G. E., Horschler, D. J., Levy, K. M., Kennedy, B. S., Famula, T. R., \& MacLean, E. L. (2021). Early-emerging and highly heritable sensitivity to human communication in dogs. Current Biology, 31(14), 3132-3136.e5. https://doi.org/10.1016/j.cub.2021.04.055 
Bshary, R., Hohner, A., Ait-el-Djoudi, K., \& Fricke, H. (2006). Interspecific communicative and coordinated hunting between groupers and giant moray eels in the Red Sea. PLoS Biology, 4(12), e431. https://doi.org/10.1371/journal.pbio.0040431

Bühler, K. (1934/1990). Theory of language: The representational function of language. John Benjamins.

Butterworth, G. (2003). Pointing is the royal road to language for babies. In S. Kita (Ed.), Pointing: Where language, culture, and cognition meet (pp. 9-33). Lawrence Erlbaum.

Calbris, G. (1990). The semiotics of French gestures. Indiana University Press.

Capirci, O., Contaldo, A., Caselli, M. C., \& Volterra, V. (2005). From action to language through gesture: A longitudinal perspective. Gesture, 5(1-2), 155-177.

Cappuccio, M. L., Chu, M., \& Kita, S. (2013). Pointing as an Instrumental Gesture: Gaze representation through indication. Humana.Mente, 24, 125-150.

Carlson, R. A., Avraamides, M. N., Cary, M., \& Strasberg, S. (2007). What do the hands externalize in simple arithmetic? Journal of Experimental Psychology: Learning, Memory, and Cognition, 33(4), 747-756.

Carpendale, J. I. M., \& Carpendale, A. B. (2010). The development of pointing: From personal directedness to interpersonal direction. Human Development, 53(3), 110-126.

Carpenter, M., Nagell, K., Tomasello, M., \& Moore, C. (1998). Social cognition, joint attention, and communicative competence from 9 to 15 months of age. Monographs of the Society for Research in Child Development, 63(4), 1-174.

Cartmill, E., Hunsicker, D., \& Goldin-Meadow, S. (2014). Pointing and naming are not redundant: Children use gesture to modify nouns before they modify nouns in speech. Developmental Psychology, 50(6), 1660-66.

Choi, B., Wei, R., \& Rowe, M. L. (2021). Show, give, and point gestures across infancy differentially predict language development. Developmental Psychology, 57(6), 851.

Clark, E. V., \& Sengul, C. J. (1978). Strategies in the acquisition of deixis. Journal of Child Language, 5, 457-475.

Clark, H. H. (2003). Pointing and placing. In S. Kita (Ed.), Pointing: Where language, culture, and cognition meet (pp. 243-268). Lawrence Erlbaum.

Clark, H. H. (2016). Depicting as a method of communication. Psychological Review, 123(3), 324-347. 
Clark, K. (1993). Leonardo da Vinci [revised edition]. Penguin Books.

Clark, H. H., Schreuder, R., \& Buttrick, S. (1983). Common ground and the understanding of demonstrative reference. Journal of Verbal Learning and Verbal Behavior, 22(2), 245-258.

Cleret de Langavant, L., Trinkler, I., Cesaro, P., \& Bachoud-Lévi, A. C. (2009).

Heterotopagnosia: When I point at parts of your body. Neuropsychologia, 47(7), 1745-1755.

Cleret de Langavant, L., Trinkler, I., Remy, P., Thirioux, B., McIntyre, J., Berthoz, A., Dupoux, E., Bachoud-Lévi, A. C. (2012). Viewing another person's body as a target object: A behavioural and PET study of pointing. Neuropsychologia, 50(8), 1801-1813.

Cochet, H., \& Vauclair, J. (2010). Pointing gestures produced by toddlers from 15 to 30 months: Different functions, hand shapes and laterality patterns. Infant Behavior and Development, 33(4), 431-441.

Collinson, W. E. (1937). Indication: A study of demonstratives, articles, and other "indicators." Language, 13(2), 5-128.

Colonnesi, C., Stams, G. J. J. M., Koster, I., \& Noom, M. J. (2010). The relation between pointing and language development: A meta-analysis. Developmental Review, 30(4), 352 366.

Cooney, S. M., Brady, N., \& McKinney, A. (2018). Pointing perception is precise. Cognition, 177, 226-233.

Cooperrider, K. (2011). Reference in action: Links between pointing and language (Doctoral dissertation). Retrieved from eScholarship (b7207917).

Cooperrider, K. (2014). Body-directed gestures: Pointing to the self and beyond. Journal of Pragmatics, 71, 1-16.

Cooperrider, K. (2016). The co-organization of demonstratives and pointing gestures. Discourse Processes, 53(8), 632-656.

Cooperrider, K., Fenlon, J., Keane, J., Brentari, D., and Goldin-Meadow, S. (2021) How pointing is integrated into language: Evidence from speakers and signers. Frontiers in Communication, 6, 567774. doi: 10.3389/fcomm.2021.567774

Cooperrider, K., \& Núñez, R. (2012). Nose-pointing: Notes on a facial gesture of Papua New Guinea. Gesture, 12(2), 103-129. 
Cooperrider, K., Núñez, R., \& Sweetser, E. (2014). The conceptualization of time in gesture. In C. Müller, A. Cienki, E. Fricke, S. Ladewig, D. McNeill, \& J. Bressem (Eds.), BodyLanguage-Communication (vol. 2) (pp. 1781-1788). Mouton de Gruyter.

Cooperrider, K., Slotta, J., \& Núñez, R. (2018). The preference for pointing with the hand is not universal. Cognitive Science, 42(4), 1375-1390.

Copeland, J. E. (2000). The grammaticalization of lexicalized manual gesture in Tarahumara. In D. Lockwood, P. H. Fries, \& J. E. Copeland (Eds.), Functional approaches to language, culture, and cognition: Papers in honor of Sydney M. Lamb (pp. 427-443). John Benjamins.

Corballis, M. C. (2008). The gestural origins of language. In N. Masataka (Ed.), The origins of language: Unraveling evolutionary forces (pp. 11-23). Springer.

Cormier, K., Schembri, A., \& Woll, B. (2013). Pronouns and pointing in sign languages. Lingua, $137,230-247$.

Davis, J. E. (2010). Hand talk: Sign language among American Indian nations. Cambridge University Press.

Dégerando, J.-M. (1800/1969). The observation of savage peoples [trans. F. C. T. Moore]. Routledge.

Degos, J. D., Bachoud-Levi, A. C., Ergis, A. M., Petrissans, J. L., \& Cesaro, P. (1997). Selective inability to point to extrapersonal targets after left posterior parietal lesions: An objectivization disorder? Neurocase, 3(1), 31-39.

Delgado, B., Gómez, J. C., \& Sarriá, E. (2011). Pointing gestures as a cognitive tool in young children: Experimental evidence. Journal of Experimental Child Psychology, 110(3), 299312.

DeLoache, J. S., Cassidy, D. J., \& Brown, A. L. (1985). Precursors of mnemonic strategies in very young children's memory. Child Development, 56(1), 125-137.

De Ruiter, J. P., Bangerter, A., \& Dings, P. (2012). The interplay between gesture and speech in the production of referring expressions: Investigating the tradeoff hypothesis. Topics in Cognitive Science, 4(2), 232-248.

De Ruiter, J. P., \& Wilkins, D. P. (1998). The synchronization of gesture and speech in Dutch and Arrernte (an Australian Aboriginal language): A cross-cultural comparison. In S. Santi (Ed.), Oralité et Gestualité (pp. 603-607). Harmattan. 
De Vos, C. (2014). The Kata Kolok pointing system: Morphemization and syntactic integration. Topics in Cognitive Science, 7(1), 150-168.

Diessel, H. (1999). Demonstratives: Form, function, and grammaticalization. John Benjamins.

Diessel, H. (2006). Demonstratives, joint attention, and the emergence of grammar. Cognitive Linguistics, 17(4), 463-489.

Diessel, H. (2012). Bühler's two-field theory of pointing and naming and the deictic origins of grammatical morphemes. In T. Breban, L. Brems, K. Davidse, \& T. Mortelmans (Eds.), New Perspectives on grammaticalization: Theoretical understanding and empirical description (pp. 35-48). John Benjamins.

Dixon, R. M. W. (2003). Demonstratives: A cross-linguistic typology. Studies in Language, $27(1), 61-112$.

Douglas, P. H., \& Moscovice, L. R. (2015). Pointing and pantomime in wild apes? Female bonobos use referential and iconic gestures to request genito-genital rubbing. Scientific Reports, 5(1), 13999. https://doi.org/10.1038/srep13999

Dupoux, E. (February 16, 2011). Human avoidance in pointing: A cultural universal? Retrieved from http://cognitionandculture.net/blogs/emmanuel-dupouxs-blog/human-avoidance-inpointing-a-cultural-universal/

Eco, U. (1976). A theory of semiotics. Indiana University Press.

Edwards, T. (2015). Bridging the gap between DeafBlind minds: interactional and social foundations of intention attribution in the Seattle DeafBlind community. Frontiers in Psychology 6,1497. doi: 10.3389/fpsyg.2015.01497

Eibl-Eibesfeldt, I. (1989). Human ethology. Aldine de Gruyter.

Emmorey, K., \& Casey, S. (2001). Gesture, thought and spatial language. Gesture, 1(1), 35-50.

Enfield, N. J. (2001). 'Lip-pointing': A discussion of form and function with reference to data from Laos. Gesture, 1(2), 185-211.

Enfield, N. J. (2009). The anatomy of meaning: Speech, gesture, and composite utterances. Cambridge University Press.

Enfield, N. J., Kita, S., \& De Ruiter, J. P. (2007). Primary and secondary pragmatic functions of pointing gestures. Journal of Pragmatics, 39(10), 1722-1741. 
Evans, N., \& Levinson, S. C. (2009). The myth of language universals: Language diversity and its importance for cognitive science. Behavioral and Brain Sciences, 32(5), 429-448.

Everett, D. L. (2005). Cultural constraints on grammar and cognition in Pirahã: Another look at the design features of human language. Current Anthropology, 46(4), 621-646.

Felician, O., Ceccaldi, M., Didic, M., Thinus-Blanc, C., \& Poncet, M. (2003). Pointing to body parts: A double dissociation study. Neuropsychologia, 41(10), 1307-1316. https://doi.org/10.1016/S0028-3932(03)00046-0

Fenlon, J., Cooperrider, K., Keane, J., Brentari, D., \& Goldin-Meadow, S. (2019). Comparing sign language and gesture: Insights from pointing. Glossa, 4(1)(2), 1-26. https://doi.org/10.5334/gjgl.499

Fenlon, J., Schembri, A., Rentelis, R., \& Cormier, K. (2013). Variation in handshape and orientation in British Sign Language: The case of the "1" hand configuration. Language \& Communication, 33(1), 69-91.

Fenlon, J., Schembri, A., Rentelis, R., Vinson, D., \& Cormier, K. (2014). Using conversational data to determine lexical frequency in British Sign Language: the influence of text type. Lingua, 143, 187-202.

Ferrara, L. (2020). Some interactional functions of finger pointing in signed language conversations. Glossa: A Journal of General Linguistics, 5(1), 88. https://doi.org/10.5334/gjgl.993

Ferrara, L., \& Hodge, G. (2018). Language as description, indication, and depiction. Frontiers in Psychology, 9(MAY), 1-15. https://doi.org/10.3389/fpsyg.2018.00716

Filippone, E. (2010). The fingers and their names in the Iranian languages. Verlag der Österreichischen Akademie der Wissenschaften.

Fillmore, C. J. (1982). Towards a descriptive framework for spatial deixis. In R. J. Jarvella \& W. Klein (Eds.), Speech, place, and action: Studies in deixis and related topics (pp. 31-59). John Wiley \& Sons.

Flack, Z. M., Naylor, M., \& Leavens, D. A. (2018). Pointing to visible and invisible targets. Journal of Nonverbal Behavior, 42(2), 221-236.

Floyd, S. (2016). Modally hybrid grammar? Celestial pointing for time-of-day reference in Nheengatú. Language, 92(1), 31-64. 
Friedman, L. A. (1975). Space, time, and person reference in American Sign Language. Language, 51(4), 940-961.

Fröhlich, M., Sievers, C., Townsend, S. W., Gruber, T., \& van Schaik, C. P. (2019). Multimodal communication and language origins: Integrating gestures and vocalizations. Biological Reviews. https://doi.org/10.1111/brv.12535

Gardner, R. A., \& Gardner, B. T. (1969). Teaching sign language to a chimpanzee. Science, 165(3894), 664-672.

Gawne, L., \& McCulloch, G. (2019). Emoji as digital gestures.Language@Internet, 17, article 2.

Genty, E., \& Zuberbühler, K. (2014). Spatial reference in a bonobo gesture. Current Biology, 24(14), 1601-1605.

Gerwing, J., \& Li, S. (2019). Body-oriented gestures as a practitioner's window into interpreted communication. Social Science and Medicine, 233, 171-180.

Goffman, E. (1959). The presentation of self in everyday life. Doubleday.

Goldin-Meadow, S., Goodrich, W., Sauer, E., \& Iverson, J. (2007). Young children use their hands to tell their mothers what to say. Developmental Science, 10(6), 778-785.

Goldin-Meadow, S., \& Mylander, C. (1984). Gestural communication in deaf children: The effects and noneffects of parental put on early language development. Monographs of the Society for Research in Child Development, 49(3-4), 1-151.

Gombrich, E. H. (1966). Ritualized gesture and expression in art. Philosophical Transactions of the Royal Society, Series B, Biological Sciences, 251(772), 393-401.

Gonseth, C., Kawakami, F., Ichino, E., \& Tomonaga, M. (2017). The higher the farther: distance-specific referential gestures in chimpanzees (Pan troglodytes). Biology Letters, 13(11), 4-7.

Goodhart, F., \& Baron-Cohen, S. (1993). How many ways can the point be made? Evidence from children with and without autism. First Language, 13(38), 225-233.

Goodwin, C. (2003). Pointing as situated practice. In S. Kita (ed.) Pointing: Where language, culture, and cognition meet (pp. 217-41). Lawrence Erlbaum.

Gordon, R., Chernyak, N., \& Cordes, S. (2019). Get to the point: Preschoolers' spontaneous gesture use during a cardinality task. Cognitive Development, 52(March), 100818.

https://doi.org/10.1016/j.cogdev.2019.100818 
Goudge, T. A. (1965). Peirce's index. Transactions of the Charles S. Peirce Society, 1(2), 52-70.

Grassmann, S., \& Tomasello, M. (2010). Young children follow pointing over words in interpreting acts of reference. Developmental Science, 13(1), 252-263.

Green, J. (2019). Embodying kin-based respect in speech, sign, and gesture. Gesture, 18, 366391.

Grünloh, T., \& Liszkowski, U. (2015). Prelinguistic vocalizations distinguish pointing acts. Journal of Child Language, 42(6), 1312-1336.

Gunter, T. C., \& Weinbrenner, J. D. (2017). When to take a gesture seriously: On how we use and prioritize communicative cues. Journal of Cognitive Neuroscience, 29(8), 1355-1367.

Gunter, T. C., Weinbrenner, J. E. D., \& Holle, H. (2015). Inconsistent use of gesture space during abstract pointing impairs language comprehension. Frontiers in Psychology, 6(February), 1-10. https://doi.org/10.3389/fpsyg.2015.00080

Hacking, I. (1981). Was there ever a radical mistranslation? Analysis, 41(4), 171-175.

Hanlon, R. E., Brown, J. W., \& Gerstman, L. J. (1990). Enhancement of naming in nonfluent aphasia through gesture. Brain and Language, 38(2), 298-314.

Hare, B., Call, J., \& Tomasello, M. (1998). Communication of food location between human and dog (Canis familiaris). Evolution of communication, 2(1), 137-159.

Hare, B., \& Tomasello, M. (2005). Human-like social skills in dogs? Trends in Cognitive Sciences, 9(9), 439-444.

Hassemer, J., \& McCleary, L. (2018). The multidimensionality of pointing. Gesture, 17(3), 416461.

Haviland, J. B. (1993). Anchoring, iconicity, and orientation in Guugu Yimithirr pointing gestures. Journal of Linguistic Anthropology, 3(1), 3-45.

Healy, C. (2012). Pointing to show agreement. Semiotica, 192, 175-195.

Hewes, G. W. (1973). Primate communication and the gestural origin of language. Current Anthropology, 14(1/2), 5-24.

Hewes, G. W. (1974). Gesture language in culture contact. Sign Language Studies, 4(1), 1-34.

Hewes, G. W. (1981). Pointing and language. In T. Myers, J. Laver, \& J. Anderson (Eds.), The cognitive representation of speech (pp. 263-269). North-Holland. 
Hewes, G. W. (1996). A history of the study of language origins and the gestural primacy hypothesis. In A. Lock \& C. Peters (Eds.), Handbook of Symbolic Evolution (pp. 571-596). Oxford University Press.

Himmelmann, N. (1996). Demonstratives in narrative discourse: A taxonomy of universal uses. In B. Fox (Ed.), Studies in Anaphora (pp. 203-252). John Benjamins.

Hindley, P. C. (2014). Nominal and imperative iconic gestures used by the Khoisan of north west Botswana to coordinate hunting. African Study Monographs, 35(4), 149-181.

Hobaiter, C., Byrne, R. W., \& Leavens, D. A. (2014). Deictic gesturing in wild chimpanzees, (Pan troglodytes)? Some possible cases. Journal of Comparative Psychology, 128(1), 82-87. Holler, J. (2010). Speakers' use of interactive gestures as markers of common ground. In S. Kopp \& I. Wachsmuth (Eds.), Gesture in embodied communication and human-computer interaction (Vol. 5934, pp. 11-22). Springer Berlin Heidelberg. https://doi.org/10.1007/9783-642-12553-9_2

Houston, K. (2013). Shady characters: The secret life of punctuation, symbols, \& other typographical marks. W. W. Norton.

Hu, F. T., Ginns, P., \& Bobis, J. (2015). Getting the point: Tracing worked examples enhances learning. Learning and Instruction, 35, 85-93.

Index. (2019). In Online Etymology Dictionary. Retrieved from https://www.etymonline.com/search?q=index

Inoue-Nakamura, N., \& Matsuzawa, T. (1997). Development of stone tool use by wild chimpanzees (Pan troglodytes). Journal of Comparative Psychology, 111(2), 159-173.

Isaacson, W. (2017). Leonardo da Vinci. Simon \& Schuster.

Iverson, J. M., \& Goldin-Meadow, S. (2001). The resilience of gesture in talk: gesture in blind speakers and listeners. Developmental Science, 4(4), 416-422.

Iverson, J. M., \& Goldin-Meadow, S. (2005). Gesture paves the way for language development. Psychological Science, 16(5), 367-371.

Jarmołowicz-Nowikow, E. (2014). How Poles indicate people and objects, and what they think of certain forms of pointing gestures. Lingua Posnaniensis, 56(1), 85-95.

Johnston, T. (2013a). Formational and functional characteristics of pointing signs in a corpus of Auslan (Australian sign language): Are the data sufficient to posit a grammatical class of "pronouns" in Auslan? Corpus Linguistics and Linguistic Theory, 9(1), 109-159. 
Johnston, T. (2013b). Towards a comparative semiotics of pointing actions in signed and spoken languages. Gesture, 13(2), 109-142.

Jones, L. A., \& Lederman, S. J. (2006). Human hand function. Oxford University Press.

Justice, L. M., \& Ezell, H. K. (2004). Print referencing: An emergent literacy enhancement strategy and its clinical applications. Language, Speech, and Hearing Services in Schools, 35(2), 185-193.

Kaplan, G. (2011). Pointing gesture in a bird - merely instrumental or a cognitively complex behavior? Current Zoology, 57(4), 453-468.

Kelly, S., Barr, D. J., Church, R. B., \& Lynch, K. (1999). Offering a hand to pragmatic understanding: The role of speech and gesture in comprehension and memory. Journal of Memory and Language, 40(4), 577-592.

Kendon, A. (1980a). A description of a deaf-mute sign language from the Enga Province of Papua New Guinea with some comparative discussion. Part I: The formational properties of Enga signs. Semiotica, 31(1/2), 1-34.

Kendon, A. (1980b). A description of a deaf-mute sign language from the Enga Province of Papua New Guinea with some comparative discussion. Part II: The semiotic functioning of Enga signs. Semiotica, 32(1/2), 81-117.

Kendon, A. (1980c). A description of a deaf-mute sign language from the Enga Province of Papua New Guinea with some comparative discussion. Part III: Aspects of utterance construction. Semiotica, 32(3/4), 245-313.

Kendon, A. (2004). Gesture: Visible action as utterance. Cambridge University Press.

Kendon, A. (2009). Language's matrix. Gesture, 9(3), 355-372.

Kendon, A. (2017). Reflections on the "gesture-first" hypothesis of language origins. Psychonomic Bulletin \& Review, 24(1), 163-170.

Kendon, A., \& Versante, L. (2003). Pointing by hand in "Neapolitan". In S. Kita (Ed.), Pointing: Where language, culture, and cognition meet (pp. 117-146). Lawrence Erlbaum.

Kettner, V. A., \& Carpendale, J. I. M. (2018). From touching to communicating forms of index finger use in the development of pointing. Gesture, 17(2), 245-267.

Kirsh, D. (1995). Complementary strategies: Why we use our hands when we think. In J. D. Moore \& J. F. Lehman (Eds.), Proceedings of the Seventheenth Annual Conference of the Cognitive Science Society (pp. 212-217). Lawrence Erlbaum. 
Kita, S. (2003). Interplay of gaze, hand, torso orientation, and language in pointing. In S. Kita (Ed.), Pointing: Where language, culture, and cognition meet (pp. 307-328). Lawrence Erlbaum.

Kita, S., \& Essegbey, J. (2001). Pointing left in Ghana: How a taboo on the use of the left hand influences gestural practice. Gesture, 1(1), 73-95.

Knoblauch, H. (2008). The performance of knowledge: Pointing and knowledge in Powerpoint presentations. Cultural Sociology, 2(1), 75-97.

Kockelman, P. (2005). The semiotic stance. Semiotica, 157(1/4), 233-304.

Korbach, A., Ginns, P., Brünken, R., \& Park, B. (2020). Should learners use their hands for learning? Results from an eye-tracking study. Journal of Computer Assisted Learning, 36(1), $102-113$.

Krajcik, C. (March 30, 2017). Snap gestures in the Lower Casamance. Retrieved from https://soascrossroads.org/2017/03/30/snap-gestures-in-the-lower-casamance/

Krause, M. A., Udell, M. A. R., Leavens, D. A., \& Skopos, L. (2018). Animal pointing: Changing trends and findings from 30 years of research. Journal of Comparative Psychology, $132(3), 326-345$.

Krehm, M., Onishi, K. H., \& Vouloumanos, A. (2014). I see your point: Infants under 12 Months understand that pointing is communicative. Journal of Cognition and Development, 15(4), 527-538. https://doi.org/10.1080/15248372.2012.736112

Kulick, D. (2019). A death in the rainforest: How a language and a way of life came to an end in Papua New Guinea. Algonquin Books.

Kusters, A. (2017). “Our hands must be connected”: visible gestures, tactile gestures and objects in interactions featuring a deafblind customer in Mumbai. Social Semiotics, 27(4), 394-410.

Laing, E., Butterworth, G., Ansari, D., Gsödl, M., Longhi, E., Panagiotaki, G., Paterson, S., Karmiloff-Smith, A. (2002). Atypical development of language and social communication in toddlers with Williams syndrome. Developmental Science, 5(2), 233-246.

Langton, S. R., \& Bruce, V. (2000). You must see the point: Automatic processing of cues to the direction of social attention. Journal of Experimental Psychology: Human Perception and Performance, 26(2), 747-757.

Larner, J. W. (1986). Judging the kitchen debate. OAH Magazine of History, 2(1), 25-27. 
Leavens, D. A. (2012). Joint attention: Twelve myths. In A. Seeman (Ed.), Joint attention: New developments in psychology, philosophy of mind, and social neuroscience (pp. 43-72). MIT Press.

Lee, R. L., \& Fraser, A. B. (2001). The rainbow bridge: Rainbows in art, myth, and science. Penn State Press.

Le Guen, O. (2011). Modes of pointing to existing spaces and the use of frames of reference. Gesture, 11(3), 271-307.

Lempert, H., \& Kinsbourne, M. (1985). Possible origin of speech in selective orienting. Psychological Bulletin, 97(1), 62-73.

Levelt, W. J. M. (2004). Speech, gesture and the origins of language. European Review, 12(4), $543-549$.

Levelt, W. J. M., Richardson, G., \& La Heij, W. (1985). Pointing and voicing in deictic expressions. Journal of Memory and Language, 24, 133-164.

Levinson, S. C. (2003). Space in language and cognition. Cambridge University Press.

Levinson, S. C. (2007). Optimizing person reference - perspectives from usage on Rossel Island. In N. Enfield, \& T. Stivers (Eds.), Person reference in interaction: Linguistic, cultural, and social perspectives (pp. 29-72). Cambridge University Press.

Levinson, S. C., \& Holler, J. (2014). The origin of human multi-modal communication. Philosophical Transactions of the Royal Society B. 10.1098/rstb.2013.0302

Lewis, D. (1976). Observations on route finding and spatial orientation among the aboriginal peoples of the Western desert region of central Australia. Oceania, 46(4), 249-282.

Lewis-Williams, D. (1986). Paintings of power: Ethnography and rock art in souther Africa. In M. Biesele, R. Gordon, \& R. Lee (Eds.), The past and future of !Kung ethnography: Critical reflections and symbolic perspectives: Essays in honor of Lorna Marshall (pp. 231-273). Helmut Buske Verlag.

Li, H., \& Cao, Y. (2019). Hands occupied: Chinese farmers use more non-manual pointing than herders. Lingua, 222, 1-9.

Liszkowski, U., Brown, P., Callaghan, T., Takada, A., \& De Vos, C. (2012). A prelinguistic gestural universal of human communication. Cognitive Science, 36, 698-713. 
Lock, A., Young, A., Service, V., \& Chandler, P. (1994). Some observations on the origins of the pointing gesture. In V. Volterra \& C. Erting (Eds.), From gesture to language in hearing and deaf children. Gallaudet University Press.

Looney, V., \& Meier, R. P. (2014). Genie's middle-finger points and signs: A case study. Gesture, 14(1), 97-107.

Lorello, M. (December 18, 2008). In piazza Babbo Natale in slip la scultura osé divide Terrasini. Retrieved from https://palermo.repubblica.it/dettaglio/in-piazza-babbo-natale-in-slip-lascultura-ose-divide-terrasini/1563883

Louwerse, M. M., \& Bangerter, A. (2010). Effects of ambiguous gestures and language on the time course of reference resolution. Cognitive Science, 34(8), 1517-1529

Lucca, K., \& Wilbourn, M. P. (2018). Communicating to learn: Infants' pointing gestures result in optimal learning. Child Development, 89(3), 941-960.

Lucca, K., \& Wilbourn, M. P. (2019). The what and the how: Information-seeking pointing gestures facilitate learning labels and functions. Journal of Experimental Child Psychology, $178,417-436$.

Lücking, A., Pfeiffer, T., \& Rieser, H. (2015). Pointing and reference reconsidered. Journal of Pragmatics, 77, 56-79.

Lüke, C., Ritterfeld, U., Grimminger, A., Liszkowski, U., \& Rohlfing, K. J. (2017). Development of pointing gestures in children with typical and delayed language acquisition. Journal of Speech, Language, and Hearing Research, 60(11), 3185-3197.

Lüke, C., Rohlfing, K. J., Grimminger, A., Liszkowski, U., \& Ritterfeld, U. (2017). In infants' hands: Identification of preverbal infants at risk for primary language delay. Child Development, 88(2), 484-492.

Luu, C. (November 19, 2017). Disney employees definitely aren't allowed to do this. Retrieved from https://www.refinery29.com/en-us/2017/11/181702/disney-parks-employees-doublefinger-point

Lyn, H., Greenfield, P. M., Savage-Rumbaugh, S., Gillespie-Lynch, K., \& Hopkins, W. D. (2011). Nonhuman primates do declare! A comparison of declarative symbol and gesture use in two children, two bonobos, and a chimpanzee. Language and Communication, 31(1), 6374. 
Mallery, G. (1882). The gesture speech of man. American Annals of the Deaf and Dumb, 27(2), 69-89.

Manwaring, S. S., Stevens, A. L., Mowdood, A., \& Lackey, M. (2018). A scoping review of deictic gesture use in toddlers with or at-risk for autism spectrum disorder. Autism \& Developmental Language Impairments, 3, 239694151775189. https://doi.org/10.1177/2396941517751891

Masataka, N. (2003). From index-finger extension to index-finger pointing: Ontogenesis of pointing in preverbal infants. In S. Kita (Ed.), Pointing: Where language, culture, and cognition meet (pp. 69-84). Lawrence Erlbaum.

Matthews, D., Behne, T., Lieven, E., \& Tomasello, M. (2012). Origins of the human pointing gesture: a training study. Developmental Science, 15(6), 817-829.

McBurney, S. L. (2002). Pronominal reference in signed and spoken language: are grammatical categories modality-dependent? In R. Meier, K. Cormier, \& D. Quinto-Pozos (Eds.), Modality and structure in signed and spoken languages (pp. 329-369). Cambridge University Press

McClave, E. (2000). Linguistic functions of head movements in the context of speech. Journal of Pragmatics, 32(7), 855-878.

McClave, E., Kim, H., Tamer, R., \& Mileff, M. (2007). Head movements in the context of speech in Arabic, Bulgarian, Korean, and African-American Vernacular English. Gesture, 7(3), 343-390.

McPharlin, P. (1942). Roman numerals, typographic leaves and pointing hands: some notes on their origin, history and contemporary use. Typophiles.

McNeill, D., Cassell, J., \& Levy, E. T. (1993). Abstract deixis. Semiotica, 95(1/2), 5-19.

Mechraoui, A., \& Noor, F. N. B. M. (2017). The direction giving pointing gestures of the Malay Malaysian speech community. Gesture, 16(1), 68-99.

Meguerditchian, A., Cochet, H., \& Vauclair, J. (2011). From gesture to language: Ontogenetic and phylogenetic perspectives on gestural communication and its cerebral lateralization. In In A. Vilain, J. L. Schwartz, C. Abry, \& J. Vauclair (Eds.), Primate communication and human language: Vocalisation, gestures, imitation, and deixis in humans and non-humans (pp. 97116). John Benjamins. 
Meier, R. P., \& Lillo-Martin, D. (2013). The points of language. Humana.Mente: Journal of Philosophical Studies, 24, 151-176.

Meissner, M., Philpott, S. B., \& Philpott, D. (1975). A dictionary of sawmill workers' signs. Sign Language Studies, 9(Winter), 309-347.

Mervis, C. B., \& Becerra, A. M. (2007). Language and communicative development in Williams syndrome. Mental Retardation and Developmental Disabilities Research Reviews, 13, 3-15.

Mesh, K. (2021). It's as far as the arm can raise: Pointing height marks target distance among the San Juan Quiahije Chatino. Lingua, 103099.

Mihas, E. (2017). Interactional functions of lip funneling gestures: A case study of Northern Kampa Arawaks of Peru. Gesture, 16(3), 432-479.

Mondada, L. (2007). Multimodal resources for turn-taking: pointing and the emergence of possible next speakers. Discourse Studies, 9(2), 194-225.

Moore, C., Dailey, S., Garrison, H., Amatuni, A., \& Bergelson, E. (2019). Point, walk, talk: Links between three early milestones, from observation and parental report. Developmental Psychology, 55(8), 1579-1593.

Moore, R. (2016). Meaning and ostension in great ape gestural communication. Animal Cognition, 19(1), 223-231.

Moreno-Núñez, A., Rodríguez, C., \& Miranda-Zapata, E. (2020). Getting away from the point: the emergence of ostensive gestures and their functions. Journal of Child Language, 47(3), 556-578.

Morford, J., \& MacFarlane, J. 2003. Frequency characteristics of American Sign Language. Sign Language Studies 3(2). 213-225.

Morgenstern, A., Caët, S., \& Limousin, F. (2016). Pointing and self-reference in French and French Sign Language. Open Linguistics, 2, 47-66.

Nazareth, A., Huang, X., Voyer, D., \& Newcombe, N. (2019). A meta-analysis of sex differences in human navigation skills. Psychonomic Bulletin and Review, 26(5), 1503-1528.

Nunberg, G. (1993). Indexicality and deixis. Linguistics and Philosophy, 16, 1-43.

Olko, J. (2014). Body language in the preconquest and colonial Nahua World. Ethnohistory, 61(1), 149-179.

O’Madagain, C., Kachel, G., \& Strickland, B. (2019). The origin of pointing: Evidence for the touch hypothesis. Science Advances, 5(7), eaav2558. https://doi.org/10.1126/sciadv.aav2558 
Orie, O. (2009). Pointing the Yoruba way. Gesture, 9(2), 237-261.

Palmquist, C., \& Jaswal, V. K. (2012). Preschoolers expect pointers (even ignorant ones) to be knowledgeable. Psychological Science, 23(3), 230-231.

Peeters, D., Krahmer, E., \& Maes, A. (2021). A conceptual framework for the study of demonstrative reference. Psychonomic Bulletin \& Review, 28(2), 409-433.

Peirce, C. S. (1940). Philosophical writings of Peirce. (J. Buchler, Ed.). Dover.

Perniss, P., \& Özyürek, A. (2015). Visible cohesion: A comparison of reference tracking in sign, speech, and co-speech gesture. Topics in Cognitive Science, 7(1), 36-60.

Petitto, L. A. (1987). On the autonomy of language and gesture: Evidence from the acquisition of personal pronouns in American sign language. Cognition, 27(1), 1-52.

Piasta, S. B., Justice, L. M., McGinty, A. S., \& Kaderavek, J. N. (2012). Increasing young children's contact with print during shared reading: Longitudinal effects on literacy achievement. Child Development, 83(3), 810-820.

Pika, S., \& Bugnyar, T. (2011). The use of referential gestures in ravens (Corvus corax) in the wild. Nature Communications, 2, 560.

Pika, S., \& Mitani, J. (2006). Referential gestural communication in wild chimpanzees (Pan troglodytes). Current Biology, 16(6), R191-R192.

Pizzuto, E. A., \& Capobianco, M. (2008). Is pointing “just” pointing? Unraveling the complexity of indexes in spoken and signed discourse. Gesture, 8(1), 82-103.

Pollick, A. S., \& de Waal, F. B. M. (2007). Ape gestures and language evolution. Proceedings of the National Academy of Sciences, 104(19), 8184-8189.

Powell, K. (December 30, 2018). Cemetery symbolism: Clasped hands and pointing fingers. Retrieved from https://www.thoughtco.com/cemetery-symbolism-clasped-hands-pointingfingers-1420808

Povinelli, D. J., Bering, J. M., \& Giambrone, S. (2003). Chimpanzees' “pointing”: Another error of the argument by analogy? In S. Kita (Ed.), Pointing: Where language, culture, and cognition meet (pp. 35-68). Laurence Erlbaum.

Povinelli, D. J., \& Davis, D. R. (1994). Differences between chimpanzees (Pan troglodytes) and humans (Homo sapiens) in the resting state of the index finger: implications for pointing. Journal of Comparative Psychology, 108(2), 134-139. 
Pyers, J. E. (2006). Indicating the body: Expression of body part terminology in American Sign Language. Language Sciences, 28(2-3), 280-303.

Quine, W. V. (1960). Word and object. MIT Press.

Quine, W. V. (1968). Ontological relativity. The Journal of Philosophy, 65(7), 185-212.

Quintilianus, Marcus Fabius (1922). The institutio oratoria of Quintilian. Translated by Harold Edgeworth Butler, Volume IV, The Loeb Classical Library. G. P. Putnam and Sons.

Ramenzoni, V. C., \& Liszkowski, U. (2016). The social reach: 8-month-olds reach for unobtainable objects in the presence of another person. Psychological Science, 27(9), 12781285.

Raum, O. (1973). The social functions of avoidances and taboos among the Zulu. Walter de Gruyter.

Richarz, A. (March 29, 2017). Why Japan's rail workers can't stop pointing at things. Retrieved from https://www.atlasobscura.com/articles/pointing-and-calling-japan-trains

Roberts, A. I., Vick, S. J., Roberts, S. G. B., \& Menzel, C. R. (2014). Chimpanzees modify intentional gestures to coordinate a search for hidden food. Nature Communications, 5, 1-8. https://doi.org/10.1038/ncomms4088

Robira, B., Pouydebat, E., San-Galli, A., Meulman, E. J. M., Aubaile, F., Breuer, T., \& Masi, S. (2018). Handedness in gestural and manipulative actions in male hunter-gatherer Aka pygmies from Central African Republic. American Journal of Physical Anthropology, $166(2), 481-491$.

Rodgers, G. (July 2, 2019). Cultural etiquette in Thailand. Retrieved from https://www.tripsavvy.com/thailand-etiquette-dos-and-donts-1458305

Roheim, G. (1925). The pointing bone. The Journal of the Royal Anthropological Institute of Great Britain and Ireland, 55, 90-114.

Rolfe, L. H. (1996). Theoretical stages in the prehistory of grammar. In A. J. Lock \& C. R. Peters (Eds.), Handbook of human symbolic evolution (pp. 776-792). Clarendon Press.

Roush, D. R. (2011). Language between bodies: A cognitive approach to understanding linguistic politeness in American sign language. Sign Language Studies, 11(3), 329-374.

Salo, V. C., Reeb-Sutherland, B., Frenkel, T. I., Bowman, L. C., \& Rowe, M. L. (2019). Does intention matter? Relations between parent pointing, infant pointing, and developing language ability. Journal of Cognition and Development, 20(5), 635-655. 
Salomons, H., Smith, K. C. M., Callahan-Beckel, M., Callahan, M., Levy, K., Kennedy, B. S., Bray, E. E., Gnanadesikan, G. E., Horschler, D. J., Gruen, M., Tan, J., White, P., vonHoldt, B. M., MacLean, E. L., \& Hare, B. (2021). Cooperative communication with humans evolved to emerge early in domestic dogs. Current Biology, 31(14), 3137-3144.e11. https://doi.org/10.1016/j.cub.2021.06.051

Sauer, E., Levine, S. C., \& Goldin-Meadow, S. (2010). Early gesture predicts language delay in children with pre- or perinatal brain lesions. Child Development, 81(2), 528-539.

Saxe, G. B., \& Kaplan, A. N. D. R. (1981). Gesture in early counting: A developmental analysis. Perceptual and Motor Skills, 53, 851-854.

Schegloff, E. A. (1984). On some gestures' relation to talk. In J. M. Atkinson \& J. Heritage (Eds.), Structures of Social Action (pp. 266-298). Cambridge University Press.

Schembri, A., Cormier, K., \& Fenlon, J. (2018). Indicating verbs as typologically unique constructions: Reconsidering verb "agreement” in sign languages. Glossa, 3(1), 1-40.

Scott-Phillips, T. (2014). Speaking our minds: Why human communication is different, and how language evolved to make it special. Macmillan International Higher Education.

Seki, K., Yajima, M., \& Sugishita, M. (1995). The efficacy of kinesthetic reading treatment for pure alexia. Neuropsychologia, 33(5), 595-609.

Sherman, W. H. (2010). Used books: Marking readers in Renaissance England. University of Pennsylvania Press.

Sherzer, J. (1973). Verbal and nonverbal deixis: The pointed lip gesture among the San Blas Cuna. Language in Society, 2, 117-131.

Sherzer, J. (1983). Kuna ways of speaking: An ethnographic perspective. University of Texas Press.

Shinn, M. W. (1900). The biography of a baby. Houghton, Mifflin.

Shwarz, H (April 8, 2015). Julia Louis-Dreyfus hates the 'Clinton thumb.' Retrieved from https://www.washingtonpost.com/news/the-fix/wp/2015/04/08/julia-louis-dreyfus-hates-theclinton-thumb/

Sibree, J. (1884). Notes on relics of the sign and gesture language among the Malagasy. The Journal of the Anthropological Institute of Great Britain and Ireland, 13, 174-183.

Smet, A. F., \& Byrne, R. W. (2013). African elephants can use human pointing cues to find hidden food. Current Biology, 23(20), 2033-2037. 
Smith, W. G., \& Kam, C. L. H. (2012). Knowing 'who she is' based on 'where she is': The effect of co-speech gesture on pronoun comprehension. Language and Cognition, 4(2), 7598.

So, W. C., Kita, S., \& Goldin-Meadow, S. (2009). Using the hands to identify who does what to whom: Gesture and speech go hand-in-hand. Cognitive science, 33(1), 115-125.

Southgate, V., Van Maanen, C., \& Csibra, G. (2007). Infant pointing: Communication to cooperate or communication to learn? Child Development, 78(3), 735-740.

Sparaci, L. (2013). Beyond the point: A basic guide to literature on pointing abilities in children with autism. Humana.Mente Journal of Philosophical Studies, 24, 177-202.

Stukenbrock, A. (2014). Pointing to an 'empty' space: Deixis am Phantasma in face-to-face interaction. Journal of Pragmatics, 74, 70-93.

Tallis, R. (2010). Michelangelo's finger: An exploration of everyday transcendence. Yale Unviersity Press.

Talmy, L. (2017). The targeting system of language. MIT Press.

Tang, M., Ginns, P., \& Jacobson, M. (2019). Tracing enhances recall and transfer of knowledge of the water cycle. Educational Psychology Review, 31, 439-455.

Tauzin, T., Bohn, M., Gergely, G., \& Call, J. (2020). Context-sensitive adjustment of pointing in great apes. Scientific Reports, 10(1), 1-10. https://doi.org/10.1038/s41598-019-56183-7

Thao, T. D. (1984). Investigations into the origin of language and consciousness. Hingham, MA: Kluwer.

Thompson, L. A., \& Massaro, D. W. (1986). Evaluation and integration of speech and pointing gestures during referential understanding. Journal of Experimental Child Psychology, 42(1), $144-168$.

Tomasello, M. (2006). Why don't apes point? In N. J. Enfield \& S. C. Levinson (Eds.), Roots of human sociality: Culture, cognition and interaction (pp. 506-524). New York: Berg.

Tomasello, M. (2008). The origins of communication. Cambridge, MA: MIT Press.

Tomasello, M., Carpenter, M., \& Liszkowski, U. (2007). A new look at infant pointing. Child Development, 78(3), 705-722.

Trumbull, J. H. (1874). On numerals in American Indian languages, and the Indian mode of counting. Transactions of the American Philological Association (1869-1896), 5(1874), 4176. 
Udell, M. A. R., Dorey, N. R., \& Wynne, C. D. L. (2008). Wolves outperform dogs in following human social cues. Animal Behaviour, 76(6), 1767-1773.

Vail, A. L., Manica, A., \& Bshary, R. (2013). Referential gestures in fish collaborative hunting. Nature communications, 4(1), 1-7.

Veà, J., \& Sabater-Pi, J. (1998). Spontaneous pointing behaviour in the wild pygmy chimpanzee (Pan paniscus). Folia Primatologica, 69(5), 289-290.

Vygotsky, L. S. (1988). The genesis of higher mental functions. In K. Richardson \& S. Sheldon (Eds.), Cognitive development in adolescence (pp. 61-80). Lawrence Erlbaum.

Wilkins, D. (2003). Why pointing with the index finger is not a universal (in sociocultural and semiotic terms). In S. Kita (Ed.), Pointing: Where language, culture, and cognition meet (pp. 171-215). Laurence Erlbaum.

Wilkins, D. P., Kita, S., \& Enfield, N. J. (2007). Ethnography of pointing-field worker's guide. In A. Majid (Ed.), Field Manual Volume 10 (pp. 89-95). Max Planck Institute for Psycholinguistics.

Windhager, S., Atzwanger, K., Bookstein, F. L., \& Schaefer, K. (2011). Fish in a mall aquarium-An ethological investigation of biophilia. Landscape and Urban Planning, 99(1), $23-30$.

Wittgenstein, L. (1953). Philosophical investigations. Basil Blackwell.

Wittgenstein, L. (2005). The big typescript. Blackwell.

Woodward, J. (1982). Single finger extension: For a theory of naturalness in sign language phonology. Sign Language Studies, 37, 289-304.

Wundt, W. (1973). The language of gestures. Mouton.

Xitco, M. J., Gory, J. D., \& Kuczaj, S. A. (2001). Spontaneous pointing by bottlenose dolphins (Tursiops truncatus). Animal Cognition, 4(2), 115-123.

Yong-Song, L. (2016). Finger names in modern Turkic languages. Central Asiatic Journal, $59(1-2), 1-42$.

Yu, N. (2000). Figurative uses of finger and palm in Chinese and English. Metaphor and Symbol, 15(3), 159-175.

Zlatev, J., Żywiczyński, P., \& Wacewicz, S. (2020). Pantomime as the original human-specific communicative system. Journal of Language Evolution, 5(2), 156-174. 